TITLE:

\title{
Thromboxane A2 synthase inhibitors prevent production of infectious hepatitis $C$ virus in mice with humanized livers.
}

\section{$\operatorname{AUTHOR}(\mathrm{S})$ :}

Abe, Yuichi; Aly, Hussein Hassan; Hiraga, Nobuhiko; Imamura, Michio; Wakita, Takaji; Shimotohno, Kunitada; Chayama, Kazuaki; Hijikata, Makoto

\section{CITATION:}

Abe, Yuichi ...[et al]. Thromboxane A2 synthase inhibitors prevent production of infectious hepatitis C virus in mice with humanized livers.. Gastroenterology 2013, 145(3): 658667.e11

\section{ISSUE DATE:}

2013-09

URL:

http://hdl.handle.net/2433/178751

\section{RIGHT:}

(C) 2013 AGA Institute. Published by Elsevier Inc.; この論文は出版社版で ありません。引用の際には出版社版をご確認ご利用ください。;This is not the published version. Please cite only the published version. 


\section{Thromboxane A2 Synthase Inhibitors Prevent Production}

\section{2 of Infectious Hepatitis C Virus in Mice with Humanized}

\section{Livers}

5 Short title: Prostanoid signals as anti-HCV targets

7 Authors:

8 Yuichi Abe $^{1,2)}$, Hussein Hassan Aly ${ }^{1,6)}$, Nobuhiko Hiraga ${ }^{3)}$, Michio Imamura ${ }^{3)}$, Takaji Wakita $^{4)}$, Kunitada Shimotohno ${ }^{5)}$, Kazuaki Chayama ${ }^{3)}$, Makoto Hijikata ${ }^{1,2)}$

1) Institute of Virus Research, Kyoto University

2) Graduate School of Biostudies, Kyoto University

3) Department of Gastroenterology and Metabolism, Applied Life Sciences, Institute of Biomedical and Health Sciences, Hiroshima University

4) Department of Virology 2, National Institute of Infectious Disease

5) Research Institute, Chiba Institute of Technology

6) Present address: Department of Virology 2, National Institute of Infectious Disease

\section{Grant support:}

19 This work was supported by grants-in-aid from the Ministry of Health, Labour and

20 Welfare of Japan.

Abbreviations: 2D, two dimensional; 3D, three dimensional; $A A C$, arachidonic acid 
1 viral agents; DAPI, 4',6-diamidino-2-phenylindole; DMEM, Dulbecco's modified

2 Eagle's medium; FBS, fetal bovine serum; FITC, fluorescein isothiocyanate; HCVcc,

$3 \mathrm{HCV}$ from cell culture; $\mathrm{IHH}$, immortalized human hepatocytes; IP, prostaglandin $\mathrm{I}_{2}$

4 receptor; LD, lipid droplet; peg-IFN, polyethylene glycol-conjugated interferon; $\mathrm{PHH}$,

5 Primary human hepatocytes; PGIS, prostaglandin $\mathrm{I}_{2}$ synthase; RT-PCR, reverse

6 transcriptase polymerase chain reaction; qRT-PCR, quantitative reverse

7 transcriptase polymerase chain reaction; siRNA, small interfering RNA; TP,

8 thromboxane $A_{2}$ receptor; TX, thromboxane; TXAS, thromboxane $A_{2}$ synthase; $T B_{2}$,

9 thromboxane $\mathrm{B}_{2}$; uPA/SCID, urokinase plasminogen activator/severe combined

10 immunodeficiency.

13 Correspondence Makoto Hijikata, PhD

14 Laboratory of Human Tumor Viruses, Department of Viral Oncology, Institute for Virus Research, Kyoto University

53, Kawaharacho, Shogoin, Sakyoku, Kyoto, 606-8507, Japan

Tel. 81-75-751-4046

FAX 81-75-751-3998

e-mail: mhijikat@virus.kyoto-u.ac.jp

Conflicts of interests: The authors disclose no conflicts

Transcript Profiling: The microarray data in this study was named as "HuSE2,

24 2Dvs3D", and registered in ArrayExpress. The accession number is E-MTAB-1491. 
2 Nucleic acid sequences: Sequencing data in this study were named as

3 "Banklt1626925 Seq1", "Banklt1626925 Seq3", and registered with GenBank. The

4 accession numbers are KF006982 and KF006984, respectively.

6 Author Contributions: Yuichi Abe was responsible for study concept and design,

7 acquisition of data, analysis and interpretation of data, drafting of the manuscript,

8 and statistical analysis. Hussein Hassan Aly, and Nobuhiko Hiraga, Michio Imamura

9 were responsible for acquisition of data, and analysis and interpretation of data.

10 Takaji Wakita, Kunitada Shimotohno, and Kazuaki Chayama were responsible for

11 critical revision of the manuscript for important intellectual content and administrative,

12 technical, or material support. Makoto Hijikata was responsible for study concept and

13 design, analysis and interpretation, drafting of the manuscript, critical revision of the

14 manuscript for important intellectual content, obtained funding, and study supervision.

16 Acknowledgements: The authors thank the following investigator and companies:

17 Dr. Michinori Kohara (Tokyo Metropolitan Institute of Medical Science, Tokyo, Japan)

18 for providing anti-HCV Core antibody; TOYOBO Co. (Osaka, Japan) for providing

19 Hollow fibers; Toray Co. (Tokyo, Japan) for providing Beraprost; Dr. Masayoshi

20 Fukasawa (National Institute of Infectious Disease, Tokyo, Japan) for helpful

21 discussion. 


\section{Abstract:}

2 Background \& Aims: A 3-dimensional (3D) culture system for immortalized

3 human hepatocytes (HuS-E/2 cells) was recently shown to support the lifecycle

4 of blood-borne hepatitis $\mathrm{C}$ virus (HCV). We used this system to identify proteins

5 that are active during the HCV lifecycle under 3D culture conditions.

6 Methods: We compared gene expression profiles of HuS-E/2 cells cultured

7 under 2D and 3D conditions. We identified signaling pathways that were

8 differentially activated in the cells, and analyzed their functions in the HCV

9 lifecycle using a recombinant HCV-producing cell culture system, with small

10 interfering (si)RNAs and chemical reagents. We investigated the effects of anti-

$11 \mathrm{HCV}$ reagents that altered these signaling pathways in mice with humanized

12 livers (carrying human hepatocytes).

13 Results: Microarray analysis showed that cells cultured under 2D vs 3D conditions expressed different levels of mRNAs encoding prostaglandin synthases. siRNA-mediated knockdown of thromboxane A2 synthase (TXAS)

16 and incubation of hepatocytes with a TXAS inhibitor showed that this enzyme is

17 required for production of infectious $\mathrm{HCV}$, but does not affect replication of the

18 HCV replication or particle release. The TXAS inhibitor and a prostaglandin I2

19 receptor agonist, which has effects that are opposite those of TXA2, reduced

20 serum levels of HCV and inhibited the infection of human hepatocytes by blood-

21 borne HCV in mice.

22 Conclusions: An inhibitor of the prostaglandin synthase TXAS inhibits

23 production of infectious HCV particles in cultured hepatocytes and HCV 
1 infection of hepatocytes in mice with humanized livers. It might therefore be

2 developed as therapeutic for HCV infection.

3 Keywords: infectious virus particle; lipid mediator; antiviral drug 


\section{Introduction}

2 Approximately 170 million people worldwide are infected with hepatitis C

3 virus $(\mathrm{HCV})^{1}$, with the majority suffering from chronic hepatitis, liver cirrhosis,

4 and/or hepatocellular carcinoma ${ }^{2}$. HCV is currently treated using a combination

5 of polyethylene glycol-conjugated interferon (peg-IFN) and ribavirin, although

6 no more than $60 \%$ of individuals adequately respond ${ }^{3}$. Recently, inhibitors of

7 HCV nonstructural proteins have been developed as direct-acting anti-viral

8 agents (DAA) to treat $\mathrm{HCV}$ effectively ${ }^{4-6}$. However, $\mathrm{HCV}$ often acquires the

9 resistance against the treatment with DAA in case of monotherapy ${ }^{7}$. Current

10 efforts are therefore focused on better understanding the lifecycle of HCV to find

11 the cellular target of novel anti-HCV drug to use the various therapeutic options.

12 A cell culture system that allows the production of recombinant infectious

$13 \mathrm{HCV}$, called HCVcc, was recently developed using a cloned HCV genome and

14 the hepatocellular carcinoma-derived Huh-7 cell line ${ }^{8-10}$. Experiments using the

15 culture system have provided novel insights on the HCV lifecycle such as

16 finding the production of infectious HCV particles near lipid droplets (LDs) and

17 endoplasmic reticulum-derived LD-associated membranes ${ }^{11}$. Huh-7 cells,

18 however, only allow the proliferation of recombinant HCV, and not blood-borne

$19 \mathrm{HCV}(\mathrm{bbHCV})$.

20 To study the lifecycle of bbHCV, we cloned immortalized human hepatocyte

$21(\mathrm{IHH})$, HuS-E/2 cells, which permitted some degree of bbHCV infection ${ }^{12}$.

22 Integrating hollow fibers into the three-dimensional (3D) culture system resulted

23 in efficient continuous proliferation of infected HCV production from the cells ${ }^{13}$. 
1 Using the improved system, we previously compared the gene expression

2 profiles of HuS-E/2 cells under the 2D and 3D culture conditions using 3 microarray analysis. This allowed us to identify signaling pathways that

4 contribute to the proliferation of $\mathrm{HCV}$, for example, peroxisome proliferator5 activated receptor $\alpha$ signaling that enhances $\mathrm{HCV}$ replication ${ }^{14}$. This result was

6 confirmed by other groups ${ }^{15,16}$, corroborating that our strategy can uncover

7 cellular events that support the proliferation of HCV. We, therefore,

8 hypothesized that leveraging the in vitro systems described above may help

9 elucidate the molecular mechanisms underlying the HCV lifecycle.

10 Prostanoids are metabolites of the arachidonic acid cascade (AAC) that 11 possess various physiologic activities ${ }^{17}$. These metabolites include

12 prostaglandin $(P G) E_{2}, D_{2}, I_{2}$, and $F_{2}$, and thromboxane $A_{2}\left(T X A_{2}\right)^{17}$. Although

13 several studies have shown that PG signaling contributes to liver regeneration ${ }^{18}$,

$14^{19}$, the physiologic functions of these lipid mediators in human hepatocytes are

15 still unknown. Interestingly, one report showed that $\mathrm{PGE}_{2}$ might support $\mathrm{HCV}$

16 genome replication in cells bearing self-replicating HCV subgenomic replicon

$17 \mathrm{RNA}^{20}$. Whether prostanoids are involved in the HCV lifecycle, however, has not

18 been precisely investigated.

19 In this study, we provide evidence that TXA 2 synthase (TXAS) is involved in

20 the formation of infectious HCV, by cell culture system, and that a TXAS

21 inhibitor and $\mathrm{PGI}_{2}$ receptor (IP) agonist that has opposite physiological effects to

$22 \mathrm{TXA}_{2}$ can be used as novel anti-HCV drugs, by using chimeric mice bearing

23 transplanted human hepatocytes ${ }^{21}$. This is the first report showing the 
1 contribution of the AAC to HCV infectivity and the potency of a prostanoid as an 2 anti-viral agent. 


\section{$1 \quad$ Materials and Methods.}

\section{Cell culture}

3 The human hepatocellular carcinoma-derived Huh-7 and Huh-7.5 cell lines

4 were cultured as described previously ${ }^{22}$. HuS-E/2 cells are IHH transduced with

5 E6 and E7 genes of human papilloma virus 18 and human telomerase reverse

6 transcriptase gene as described previously ${ }^{12} .2 \mathrm{D}$ and 3D culture conditions for

7 HuS-E/2 cells were as described previously ${ }^{12}$.

9 Reagents and antibodies

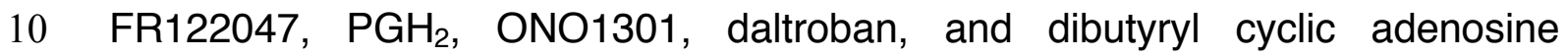

11 monophosphate (cAMP) sodium salt were purchased from Sigma-Aldrich

12 (Missouri, USA). Cyclooxygenase (COX)-2 inhibitor 1 and Ozagrel were

13 purchased from Santa Cruz Biotechnology (California, USA). U-46619 was purchased from Cayman Chemical (Michigan, USA). Beraprost was a generous

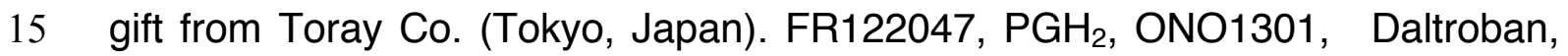

16 COX-2 inhibitor1, Ozagrel, Beraprost, and Calucium ionophore were dissolved

17 in DMSO. U-46619 and $\mathrm{TXB}_{2}$ were dissolved in methyl acetate. Dibutyryl cAMP

18 was dissolved in water. The effect of each reagent on cell viability was analyzed

19 using a Cell Proliferation Kit 2 (Roche, Basel, Switzerland) based on the 20 manufacturer's instruction. An antibody specific for Core protein (antibody 32-1)

21 was a gift from Dr. Michinori Kohara (Tokyo Metropolitan Institute of Medical

22 Science, Tokyo, Japan). Rabbit polyclonal anti-NS5A protein CL1 antibody and 23 anti-HCV protein antibody in human serum were described previously ${ }^{11}$. 


\section{Microarray analysis}

3 Total RNA purified from HuS-E/2 cells cultured under 2D or 3D conditions in the

4 absence of HCV infection was analyzed with a 3D-Gene human chip 25k (Toray,

5 Tokyo, Japan) to compare gene expression profiles as described previously ${ }^{14}$.

6 The accession number of the results is as "E-MTAB-1491" in ArrayExpress.

8 Production of HCVcc and sample preparation

9 HCVcc was produced from the Huh-7 or Huh-7.5 cells transfected with in vitro

10 synthesized $\mathrm{JFH} 1^{\mathrm{E} 2 \mathrm{FL}}$ or $\mathrm{J6} / \mathrm{JFH} 1$ RNA as described previously ${ }^{11}$. The

11 transfected cells and culture medium were harvested at four days post-

12 transfection. For JFH1 ${ }^{\mathrm{E} 2 \mathrm{FL}}$ RNA-transfected Huh-7 cells treated with TXAS-

13 specific small interfering RNA (siRNA), cells and culture medium were

14 harvested at 3 days post-transfection. Culture medium including HCVcc was

15 concentrated used for infection experiments as described previously ${ }^{11}$.

16 Concentrated culture medium from JFH1 RNA-transfected Huh-7 cells was

17 fractionated as described previously ${ }^{11}$. Infectivity titer in each fraction was

18 analyzed by focus-formation assay, which was determined by the average

19 number of HCV-positive foci.

21 Reverse transcriptase polymerase chain reaction (RT-PCR) and 
1 Total RNA was isolated from the cells and medium using Sepasol I Super and

2 Sepasol II (Nacalai Tesque), respectively, according to the manufacturer's

3 instructions. Using $200 \mathrm{ng}$ of total RNA as a template, we performed RT-PCR

4 and qRT-PCR with a one-step RNA PCR kit and one-step SYBR Primescript

5 RT-PCR kit 2 (Takara, Shiga, Japan), respectively, according to the

6 manufacturer's instructions. Information on both experiments was shown in

7 Supplemental Table 1 and 2.

8

9 Infection of HCVcc

10 Infection experiment of HCVcc and detection of infected Huh-7.5 cells by

11 indirect immunofluorescence analysis were performed mainly as described

12 previously ${ }^{11}$. The number of infection positive cells detected in $4 \times 10^{4}$ target

13 cells one day after infection with HCVcc including $10^{7}$ copies of RNase resistant

14 HCV genome was defined as the specific infectivity in the infection experiments

15 in our protocol.

17 Indirect immunofluorescence analysis

$18 \mathrm{HCV}$ proteins were examined in cells using a Leica SP2 confocal microscope

19 (Leica, Heidelberg, Germany) and infected cells were counted using a BioZero

20 fluorescence microscope (Keyence, Tokyo, Japan).

Preparation of intracellular HCV particles

23 Intracellular HCV particles were prepared as described previously ${ }^{23}$ 
2 Pharmacological test in chimeric mice bearing transplanted human

3 hepatocytes

$4 \quad$ All mouse studies were conducted at Hiroshima University and accorded with

5 the guidelines of the local committee for animal experiments. Chimeric mice

6 transplanted with human hepatocytes were generated as described previously ${ }^{21}$.

7 The experimental protocol was approved by the Ethics Review Committee for

8 Animal Experimentation of the Graduate School of Biomedical Sciences

9 (Hiroshima University). The reagents were first administered 1 week after the

10 chimeric mice were infected with $1.0 \times 10^{5}$ titer of bbHCV. ONO1301 was

11 injected subcutaneously at a dose of $200 \mu \mathrm{g}$ per mouse. Beraprost and Ozagrel

12 were orally administrated at a dose of $10 \mu \mathrm{g}$ and $300 \mu \mathrm{g}$ per mouse,

13 respectively. For positive control experiment, Telaprevir was administrated as

14 described previously ${ }^{24}$. All reagents were administrated twice each day. Serum

15 samples were collected at 2, 3, and 4 weeks after starting the treatments. HCV

16 RNA levels in the samples were evaluated in quantitative RT-PCRs.

18 Statistical Analyses of Data

19 The significance of differences in the means was determined by Student's t test 20 or Wilcoxon signed-rank test (Fig. 7 and Supplemental Fig. 14). 
1 Expression of PG synthase mRNA in HuS-E/2 cells cultured under 3D

2 conditions

3 To identify signaling pathways that contribute to HCV proliferation under the 3D

4 culture conditions, we compared the gene expression profiles of 2D- and 3D-

5 cultured HuS-E/2 cells as described previously ${ }^{14}$. We found that the expression

6 of 984 genes was up-regulated more than two times in both of two types of 3D-

7 cultured HuS-E/2 cells, and that of 1491 genes was down-regulated less than

8 half time. For the two 3D conditions, we identified the expression of a set of

9 genes encoding enzymes of the AAC. The expression levels of mRNAs for AAC

10 enzymes, COX1, $\mathrm{PGD}_{2}$ synthase, and TXAS increased in HuS-E/2 cells

11 cultured under the $3 \mathrm{D}$ conditions (Fig. 1A), while those for $P G E_{2}$ and $P G I_{2}$

12 synthases (PGIS) decreased (Fig. 1A). These results were confirmed by qRT-

13 PCR analysis (Fig. 1A, gray bars). The relative protein levels of those enzymes

14 in $2 D$ and $3 D$ cultured HuS-E/2 cells reflected the quantitative difference of

15 those mRNAs, except PGDS (Fig. 1B). The expression of those genes and the

16 production of those proteins were also observed in the liver tissues from

17 patients with hepatitis $\mathrm{C}$, suggesting the functional roles of those products in the

18 human liver (Supplemental Fig. 1).

\section{The AAC contributes to infectious HCV production}

21 To assess whether the AAC plays roles in the HCV lifecycle, the contributions of

22 the AAC rate-limiting enzymes COX1 and COX2 were examined using the JFH1

23 cell culture system. We first investigated the role of COX1, of which gene is 
1 known to be a constitutively expressed in general, by adding the COX1 inhibitor

2 FR122047 to JFH1 RNA-transfected cell cultures. Even at the higher 3 concentrations, FR122047 did not markedly affect the amount of HCV RNA in

4 the medium or cells (Fig. 2A, black and white bars) with a little cytotoxicity at 10

$5 \quad \mu \mathrm{M}$. Nevertheless, FR122047 dose-dependently decreased the infectivity of

$6 \mathrm{HCV} c \mathrm{c}$ in the culture medium (Fig. 2B, C). As the infection experiment using

7 lower titer of HCVcc from inhibitor treated cells showed that the inhibitor

8 affected the number of infection positive focus but not the number of the cells in

9 a focus (Fig. 2C), the treatment of COX1 inhibitor seemed to decrease the

10 focus-forming ability of HCVcc. Next, the contribution of inducible COX2 was

11 examined using COX2 inhibitor 1. The inhibitor, however, did not affect the

12 infectivity of HCVcc in the medium (Supplemental Fig. 2A, B), probably because

13 of the lack of COX2 gene expression in Huh-7 cells (Supplemental Fig. 2C and

$143 \mathrm{~A})$. These data suggested that COX1 and the AAC play a role in infectious

15 HCVcc production without significant effects on HCV genome replication or 16 particle release from the cells.

18 TXAS plays a key role in infectious HCV production

19 To further examine the contribution of the AAC to infectious HCVcc production, 20 we focused on TXAS, because, like COX1 mRNA, TXAS mRNA levels 21 increased in HuS-E/2 cells cultured under 3D conditions. Although $\mathrm{PGD}_{2}$ synthase mRNA levels also increased, this synthase was unlikely to contribute

23 to these processes because we did not detect $P G D_{2}$ synthase mRNA in Huh-7 
1 cells in the JFH1 cell culture system (Supplemental Fig. 3A). Using siRNA- and

2 shRNA-mediated suppression of mRNA expression, we found that reducing

3 TXAS mRNA levels in HCVcc-producing Huh-7 cells did not significantly affect

4 the amount of HCV RNA in the medium or cells (Fig. 3B and Supplemental Fig.

$54 \mathrm{~B}$, black and white bars), whereas HCVcc in the medium was less infectious,

6 as was observed when the cells treated with FR122047 (Fig. 3C and

7 Supplemental Fig. 4C). Treatment with the TXAS inhibitor Ozagrel also dose-

8 dependently suppressed infectious HCVcc production without significantly

9 affecting HCV RNA levels in the medium or cells (Fig. 3D, E). Similar effects of

10 Ozagrel were observed in another HCV cell culture system using Huh-7.5 cells

11 and chimeric recombinant J6/JFH1 HCV, which encoded different structural

12 proteins from $\mathrm{JFH}_{1}{ }^{9}$ (Supplemental Fig. 5), indicating that our results were not

13 specific to the JFH1 cell culture system. Furthermore, the treatment with $\mathrm{PGH}_{2}$,

14 a product of COX1 and a substrate of TXAS, showed to increase the infectivity

15 of HCVcc without effect on the HCV replication and egression despite short half-

16 life of $\mathrm{PGH}_{2}$ (Supplemental Fig. 6). These data suggested that the AAC, in

17 particular TXAS activity and probably $\mathrm{TXA}_{2}$ produced from $\mathrm{PGH}_{2}$ by $\mathrm{TXAS}$

18 activity, contributes to infectious HCV production.

$\mathrm{TXA}_{2}$ receptor (TP) is not required for TXAS-dependent regulation of

21 infectious HCV production

22 TXA $_{2}$ exerts its physiologic functions through TP on plasma membranes ${ }^{17}$. To examine the contribution of $\mathrm{TXA}_{2} / \mathrm{TP}$ signaling, we investigated the effects of 
1 the TP agonist U-46619 in our system. Regardless of dose, however, U-46619

2 did not affect infectious HCVcc production in the culture system (Supplemental

3 Fig. 7A, B). Treating Huh-7-derived cell lines with the TP agonist did not

4 increase the calcium ion concentration-a major downstream effect of TXA $/ T P$

5 signaling - even though the activity of U-46619 was confirmed in HEK293

6 cells $^{17}$ (Supplemental Fig. 8A). We also evaluated the activity of U-46619 in

7 terms of TP dependent-activation of Rho and observed the Rho-dependent

8 stress fiber formation induced with U-46619 in HEK293 cells (Supplemental Fig.

9 8B). In addition, the level of TP mRNA was, if any, quite low in human

10 hepatocyte derived cells and $\mathrm{PHH}$, although the only a small amount of the

11 mRNA was detected in HuS-E/2 cells (Supplemental Fig. 3B). These data

12 suggested that $\mathrm{TXA}_{2} / \mathrm{TP}$ signal transduction is deficient in Huh-7-derived cell

13 lines.

14 To determine whether TP on the Huh-7 cells was saturated with endogenous

$15 \mathrm{TXA}_{2}$ ligand, we examined the effects of $\mathrm{U}-46619$ in the presence of Ozagrel. U-

1646619 , however, did not rescue the Ozagrel-mediated suppression of infectious

17 HCVcc production (Fig. 4A, B). Additionally, the TP antagonist daltroban did not

18 affect infectious HCVcc production (Fig. 4C, D). These data indicated that TP-

19 mediated signaling is not involved in TXAS-dependent regulation of infectious

20 HCVcc production. Additionally, we examined whether thromboxane $B_{2}$

$21\left(\mathrm{TXB}_{2}\right)$ - a stable metabolite of $\mathrm{TXA}_{2}$ that does not activate TP-could be used

22 to replace TXAS during infectious $\mathrm{HCV} c \mathrm{c}$ production. $\mathrm{TXB}_{2}$ did not counteract

23 the effects of Ozagrel (Fig. 4A, B), and did not by itself affect the HCV lifecycle 
1 (Supplemental Fig. 7A, B). These data suggested that $\mathrm{TXA}_{2}$ or an unidentified

2 metabolite of $\mathrm{TXA}_{2}$ acts as a TP-independent regulator of infectious $\mathrm{HCV}$ 3 production (see Discussion).

4

5 TXAS-derived signaling contributes to HCV infectivity

6 A previous study revealed that infectious HCV is produced near LDs to which

7 HCV proteins are recruited ${ }^{6}$. As shown in Fig. 5A, inhibiting TXAS did not

8 markedly affect the locations of the viral proteins Core and NS5A around LDs,

9 suggesting that TXAS-derived signaling does not contribute to the recruitment of

$10 \mathrm{HCV}$ proteins to the LDs. Next, to examine whether TXAS-mediated signaling

11 drives the egression of infectious HCVcc from the cells, we analyzed

12 intracellular HCVcc in cells treated with Ozagrel. Levels of intracellular HCVcc

13 RNA in Huh-7 cells treated with or without Ozagrel were equivalent (Fig. 5B).

14 Nevertheless, the infectivity of intracellular HCVcc from the cells treated with

15 Ozagrel was markedly decreased as was that of HCVcc in the medium (Fig. 5C).

16 This result indicated that TXAS-derived signaling is not involved in the release

17 of infectious HCV particles. Taken together, it seemed likely that TXAS-derived

18 signaling plays a role on infectious particle formation in the cells.

Inhibition of TXAS changes the physicochemical properties of HCVcc

21 We next analyzed HCVcc produced from cells treated with Ozagrel using 22 sucrose density gradient ultracentrifugation. As reported previously ${ }^{11}$, two types 23 of fractions containing either highly infectious, low-density HCVcc (peak fraction 
1 no. 6) or less infectious, high-density HCVcc (peak fraction no. 5) were obtained

2 using samples derived from cells without treatment with Ozagrel, indicating that

3 infectious HCVcc was mainly present in fraction no. 6 (Fig. 6, white bars, upper

4 and lower panels). On the other hand, analyzing Ozagrel-treated cells revealed

5 decreased levels of HCV RNA in fraction no. 6 (Fig. 6, solid lines, upper and

6 lower panels). Of note, the amount of HCV RNA in fraction no. 5 remained

7 similar with or without Ozagrel treatment (Fig. 6, lower panel). These results

8 suggested that inhibition of TXAS-mediated signaling changed the

9 physicochemical characteristics of HCVcc, resulting in altered infectivity.

11 A TXAS inhibitor and IP agonists inhibit early HCV expansion in bbHCV12 infected chimeric mice

13 Finally, we examined the in vivo anti-HCV effects of a TXAS inhibitor using bbHCV and UPA/SCID mice bearing transplanted human hepatocytes. The IP agonist Beraprost was also tested, because $\mathrm{PGI}_{2}$ produces effects opposite to

$16 \mathrm{TXA}_{2}$ during several physiologic processes, including vascular constriction in

17 humans ${ }^{25}$. Both drugs delayed the increase in serum levels of HCV RNA (Fig. 7).

18 Of note, even 4 weeks after treatment, Beraprost reduced serum HCV RNA

19 levels to less than a quarter of those observed in control mice (Fig. 7). Our

20 results indicated that these drugs may inhibit HCV proliferation in vivo, and that

21 inhibition of TXAS-derived signaling and activation of IP-mediated $\mathrm{PGI}_{2}$ 22 signaling can control HCV proliferation. Although we examined the effects of the 23 PGIS and IP agonist on the HCV lifecycle using the HCVcc-producing cell 
1 culture system, Beraprost did not result in any notable changes (Supplemental

2 Fig. 9). To examine whether the Huh-7 cells respond to the IP agonist, we

3 assessed cAMP signaling using a plasmid bearing cAMP responsive elements

4 in a promoter upstream of the luciferase gene; cAMP signaling is a major

5 intracellular signaling pathway that is activated by IP agonists. The IP agonist,

6 however, did not activate cAMP signaling in Huh-7 cells even though the

7 pathway was activated in HuS-E/2 cells.

8 As another candidate anti-HCV drug, we examined the effect of ONO1301,

9 possessing both TXAS inhibitor and IP agonist activities, in the humanized

10 chimeric mice. ONO1301 produced the most robust suppression of HCV

11 infections (Fig. 7). The effects of ONO1301 were also studied in the HCVcc-

12 producing cell cultures; like Ozagrel. ONO1301 suppressed infectious HCV

13 production (Supplemental Fig. 10), although ONO1301 did not activated cAMP

14 signaling in Huh-7 cells (Supplemental Fig. 11). Slight decrease of HCVcc

15 egression, however, caused by the treatment with ONO1301 at high

16 concentrations might be of note. These results further supported our conclusion

17 that TXAS-mediated signaling contributes to infectious HCV production,

18 although the functional role of $\mathrm{PGI}_{2}$ in this process is still unknown. 


\section{Discussion}

2 In this study, we showed that TXAS is involved in the development of infectious HCV.

3 Administration of a TXAS inhibitor inhibited early stages of HCV proliferation post4 infection in a chimeric mouse model. These results suggest that TXAS-mediated

5 infectious HCV production is a potential target for novel anti-HCV therapies.

6 We first found that inhibiting COX1 and TXAS decreased the infectivity of HCVcc in the

7 culture medium without any significant effects on viral genome replication and particle

8 egression (Fig. 2 and 3). In addition, we showed that inhibition of TXAS did not affect

9 the release of infectious HCVcc from the cells (Fig. 5). Thus, we concluded that TXAS

10 probably regulates $\mathrm{HCV}$ particle maturation and the development of infectivity.

11 Knockdown of apolipoprotein E, heat shock protein 70, and annexin A2 expression was 12 previously shown to inhibit infectious HCVcc production ${ }^{26}$. Of note, decreased 13 expression of these host factors reduced the production of HCVcc in the culture medium 14 as well as intracellular HCVcc levels in HCVcc-producing cells, suggesting that TXAS is 15 playing a different role in HCVcc production. Moreover, our results suggest that TXAS is 16 the first host factor that has been shown to contribute only to the development of HCV 17 infectivity.

18 A previous study reported that infectious HCVcc is produced near LDs ${ }^{11}$. The HCV 19 proteins Core and NS5A are located on and nearby LDs, respectively, suggesting a role 20 in the production of infectious $\mathrm{HCVCc}^{11}$. Because LD localization of these proteins was 21 not affected by the TXAS inhibitor (Fig. 5A), TXAS is probably required after these viral 22 proteins are recruited to LDs. 
1 Several studies have shown that the buoyant density of infectious HCVcc differs

2 slightly from that of noninfectious $\mathrm{HCVcc}^{11,27,28}$. Infectious and noninfectious HCVcc are

3 found in lower and higher density fractions, respectively. In the present study, inhibition

4 of TXAS reduced the amount of HCVcc in the lower density fraction (fraction 6)

5 containing the infectious particles, whereas levels of primarily noninfectious HCVcc

6 particles in the higher density fraction (fraction 5) were not affected (Fig. 6). These

7 results mirrored previously reported data about NS5A mutant $\mathrm{HCV} c \mathrm{c}$, which do not

8 produce infectious particles ${ }^{11}$. These results suggested that TXAS might be required to

9 produce infectious HCVcc near the LDs.

10 Studies with treatments with methyl- $\beta$-cyclodextrin or lipoprotein lipase have shown

11 that changing the physicochemical properties of $\mathrm{HCVCc}^{29,3028,29}$, in which the peak

12 density fraction containing HCVcc shifted higher, diminished the infectivity of the

13 particles ${ }^{29,30}$. As TXAS inhibitors did not show the apparent shift to a higher density (Fig.

14 6), future molecular analyses of HCVcc particles should be required to reveal the

15 underlying structural mechanisms for HCV infectivity.

16 Prostanoids play various physiologic functions, including regulatory roles in muscle and

17 blood vessels ${ }^{17}$. Although inhibition of TXAS decreased the infectivity of HCVcc (Fig. 3),

18 the identity of the relevant prostanoid and how that product functions in the development

19 of infectious HCV are currently unclear. As the treatment of $\mathrm{PGH}_{2}$, a substrate of TXAS,

20 caused the increase of infectious HCV production (Supplemental Fig. 6), it seemed to

21 be ruled out the possibility that supposedly accumulated $\mathrm{PGH}_{2}$ by the treatment of

22 TXAS inhibitor play a role in the inhibition. Although we analyzed the total fatty acids in 
1 the HCV infected Huh-7.5 cells treated with and without Ozagrel, the compositions of

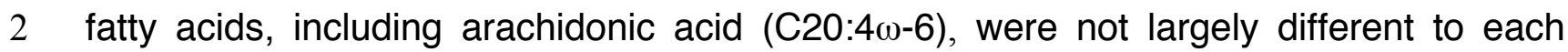

3 other (Supplemental Fig. 12), suggesting, at least, that the effect of Ozagrel is not due

4 to major change of fatty acid composition.

5 The activity of the TXAS product $\mathrm{TXA}_{2}$ was not directly examined, because its half-life

6 is quite short ${ }^{31}$. Usually, $\mathrm{TXA}_{2}$ activity is measured using stable agonists and

7 antagonists of TP. We showed, however, that TP-mediated signaling is not related to

8 the processes examined in the current study (Fig.4) It seemed likely that TXA $\mathrm{A}_{2}$ itself or

9 an unidentified metabolite of $\mathrm{TXA}_{2}$ mediates the development of HCV infectivity in a TP-

10 independent manner. $P \mathrm{PI}_{2}$ and the $P G D_{2}$ metabolite $15 d-P G J_{2}$ have been identified as

11 ligands of PPAR $\delta$ and $\gamma$, respectively ${ }^{32,33}$. Therefore, the TXAS product may act as a

12 ligand of various nuclear receptors to regulate infectious $\mathrm{HCV}$ production. In the $\mathrm{PHH}$

13 and the liver of chimeric mice transplanted with human hepatocyte, the expression of

14 human TP mRNA was not observed (Supplemental Fig. 3A and 13), although that was

15 detected in human liver tissue, consisting of many types of cells (Supplemental Fig. 13).

16 It may be true, therefore, that TP gene is not largely expressed in human hepatocytes in

17 the liver as with Huh-7 cells. Taken together, it is probable that infectious HCV are

18 produced in TP-independent manner in human liver infected with HCV. Further studies

19 regarding the TP-independent roles of TXAS products in hepatocytes may be required

20 to elucidate the mechanisms of infectious HCV formation.

21 Recently, various drugs targeting viral proteins have been developed, resulting in more

$22 \mathrm{HCV}$-specific therapeutic profiles than those of conventional drugs ${ }^{34}$. Monotherapy with 
1 an HCV-specific drug, however, sometimes fails to clear the HCV infection because of

2 rapidly emerging resistant variants ${ }^{35}$. We found that a TXAS inhibitor and IP agonists

3 suppressed early-stage expansion of bbHCV post-infection of chimeric mice bearing

4 human hepatocytes (Fig. 7). These results clearly indicate that the TXAS inhibitor and

5 IP agonist are novel candidates for anti-HCV drugs. In this experiment, the effects of an

6 IP agonist and the TXAS inhibitor were compared, because TXA $\mathrm{A}_{2}$ and IP agonists have

7 opposite clinical effects ${ }^{20}$. This implies that the IP agonist may have suppressed the

8 effects of TXAS in the bbHCV-infected transplanted human hepatocytes. Contrary to our

9 expectations, however, neither siRNA-mediated knockdown of PGIS expression nor

10 treatment with the IP agonist Beraprost affected HCV genome replication, particle

11 egression, or HCVcc infectivity (Supplemental Fig. 9). The responsiveness of Huh-7

12 cells to the IP agonist was then examined by monitoring activation of cAMP signaling, a

13 pathway that is normally activated downstream of IP. The results demonstrated that

14 Huh-7 cells were deficient in signaling from IP to intracellular cAMP production

15 (Supplemental Fig. 11). Although the therapeutic mechanism of action for the IP agonist

16 in the chimeric mice has not been clarified yet, the IP agonist may signal through IP to

17 counteract TXA 2 signaling and suppress the effects of endogenous TXAS products on

18 the formation of infectious HCV. In this in vivo experiments, the effect of drugs waned

19 over time, especially in the case of Ozagrel. We examined the infectivity and the

20 sensitivity against treatment with Ozagrel of HCV from the mice with the first drug

21 treatment by secondary infection experiment. The results showed that HCV proliferated

22 in the secondarily infected chimeric mice irrespective of the treatment of Ozagrel 
1 (Supplemental Fig. 14), suggesting that HCV proliferating in the chimeric mice with first

2 treatment acquired the resistance against Ozagrel. We analyzed partial genomic

3 sequences of the drug resistant HCVs by the direct sequencing method. We found that

468 base substitutions, ten of which was accompanied with amino acid substitution, were

5 present in such HCV genomes, compared to those in the mice untreated with the drug

6 (Supplemental Fig. 15). This indicated that HCV, of which genome included a large

7 number of base substitutions, actually proliferated in the chimeric mouse treated with

8 Ozagrel. Further study of such drug resistant HCV, for examples, the reverse genetics

9 analysis using recombinant HCV system, will help to reveal the molecular mechanisms

10 of medicinal effect of this drug and the infectious HCV production. Furthermore, these

11 results might demonstrate the needs to find the optimum dose of TXAS inhibitor for the

12 effective therapy and to use this drug as one of options with different action mechanism

13 for the multi-drug therapy. 


\section{$1 \quad$ References}

2 1. Wasley A, Alter MJ. Epidemiology of hepatitis C: geographic differences and temporal trends. Semin Liver Dis 2000;20:1-16.

2. Younossi Z, Kallman J, Kincaid J. The effects of HCV infection and management on health-related quality of life. Hepatology 2007;45:806-816.

3. Fried MW, Shiffman ML, Reddy KR, et al. Peginterferon alfa-2a plus ribavirin for chronic hepatitis C virus infection. N Engl J Med 2002;347:975-982.

4. Gao M, Nettles RE, Belema M, et al. Chemical genetics strategy identifies an HCV NS5A inhibitor with a potent clinical effect. Nature 2010;465:96-100.

5. Chayama K, Takahashi S, Toyota J, et al. Dual therapy with the nonstructural protein $5 \mathrm{~A}$ inhibitor, daclatasvir, and the nonstructural protein 3 protease inhibitor, asunaprevir, in hepatitis $\mathrm{C}$ virus genotype $1 \mathrm{~b}$-infected null responders. Hepatology 2012;55:742-748.

6. Lin C, Kwong AD, Perni RB. Discovery and development of VX-950, a novel,

17 7. Sarrazin C, Zeuzem S. Resistance to direct antiviral agents in patients with hepatitis C virus infection. Gastroenterology 2010;138:447-462.

8. Wakita T, Pietschmann T, Kato T, et al. Production of infectious hepatitis C virus in tissue culture from a cloned viral genome. Nat Med 2005;11:791-796.

9. Lindenbach BD, Evans MJ, Syder AJ, et al. Complete replication of hepatitis C virus in cell culture. Science 2005;309:623-626.

10. Zhong J, Gastaminza P, Cheng G, et al. Robust hepatitis C virus infection in vitro. Proc Natl Acad Sci U S A 2005;102:9294-9299. 
1 11. Miyanari $\mathrm{Y}$, Atsuzawa K, Usuda N, et al. The lipid droplet is an important organelle for hepatitis C virus production. Nat Cell Biol 2007;9:1089-1097.

12. Aly $\mathrm{HH}$, Watashi $\mathrm{K}$, Hijikata $\mathrm{M}$, et al. Serum-derived hepatitis $\mathrm{C}$ virus infectivity in interferon regulatory factor-7-suppressed human primary hepatocytes. J Hepatol 2007;46:26-36.

13. Aly HH, Qi Y, Atsuzawa K, et al. Strain-dependent viral dynamics and viruscell interactions in a novel in vitro system supporting the life cycle of bloodborne hepatitis C virus. Hepatology 2009;50:689-696.

14. Aly HH, Shimotohno K, Hijikata M. 3D cultured immortalized human hepatocytes useful to develop drugs for blood-borne HCV. Biochem Biophys Res Commun 2009;379:330-334.

15. Chockalingam K, Simeon RL, Rice CM, et al. A cell protection screen reveals potent inhibitors of multiple stages of the hepatitis $\mathrm{C}$ virus life cycle. Proc Natl Acad Sci U S A 2010;107:3764-3769.

16. Gastaminza P, Whitten-Bauer C, Chisari FV. Unbiased probing of the entire hepatitis $\mathrm{C}$ virus life cycle identifies clinical compounds that target multiple aspects of the infection. Proc Natl Acad Sci U S A 2010;107:291-296.

17. Bos CL, Richel DJ, Ritsema T, et al. Prostanoids and prostanoid receptors in signal transduction. Int J Biochem Cell Biol 2004;36:1187-1205.

18. Little P, Skouteris GG, Ord MG, et al. Serum from partially hepatectomized rats induces primary hepatocytes to enter $S$ phase: a role for prostaglandins? J Cell Sci 1988;91 ( Pt 4):549-553. 
1 19. Rudnick DA, Perlmutter DH, Muglia LJ. Prostaglandins are required for CREB activation and cellular proliferation during liver regeneration. Proc Natl Acad Sci U S A 2001;98:8885-8890.

20. Waris $G$, Siddiqui $A$. Hepatitis $C$ virus stimulates the expression of cyclooxygenase-2 via oxidative stress: role of prostaglandin E2 in RNA replication. J Virol 2005;79:9725-9734.

21. Tateno C, Yoshizane $\mathrm{Y}$, Saito N, et al. Near completely humanized liver in mice shows human-type metabolic responses to drugs. Am J Pathol 2004;165:901-912.

22. Kushima Y, Wakita T, Hijikata M. A disulfide-bonded dimer of the core protein of hepatitis $\mathrm{C}$ virus is important for virus-like particle production. $\mathrm{J}$ Virol 2010;84:9118-9127.

23. Gastaminza P, Kapadia SB, Chisari FV. Differential biophysical properties of infectious intracellular and secreted hepatitis C virus particles. J Virol 2006;80:11074-11081.

24. Kamiya N, Iwao E, Hiraga N, et al. Practical evaluation of a mouse with chimeric human liver model for hepatitis $C$ virus infection using an NS3-4A protease inhibitor. J Gen Virol 2010;91:1668-1677.

25. Flavahan NA. Balancing prostanoid activity in the human vascular system. Trends Pharmacol Sci 2007;28:106-110.

26. Bartenschlager R, Penin F, Lohmann V, et al. Assembly of infectious hepatitis C virus particles. Trends Microbiol 2011;19:95-103. 
1 27. Andre P, Komurian-Pradel F, Deforges S, et al. Characterization of low- and very-low-density hepatitis C virus RNA-containing particles. J Virol 2002;76:6919-6928.

28. Nielsen SU, Bassendine MF, Burt AD, et al. Association between hepatitis C virus and very-low-density lipoprotein (VLDL)/LDL analyzed in iodixanol density gradients. J Virol 2006;80:2418-2428.

29. Aizaki H, Morikawa K, Fukasawa M, et al. Critical role of virion-associated cholesterol and sphingolipid in hepatitis C virus infection. J Virol 2008;82:5715-5724.

30. Shimizu Y, Hishiki T, Sugiyama K, et al. Lipoprotein lipase and hepatic triglyceride lipase reduce the infectivity of hepatitis $\mathrm{C}$ virus (HCV) through their catalytic activities on HCV-associated lipoproteins. Virology 2010;407:152-159.

31. Gryglewski RJ. Prostacyclin among prostanoids. Pharmacol Rep 2008;60:311.

32. Forman BM, Tontonoz P, Chen J, et al. 15-Deoxy-delta 12, 14-prostaglandin $\mathrm{J} 2$ is a ligand for the adipocyte determination factor PPAR gamma. Cell 1995;83:803-812.

33. Gupta RA, Tan J, Krause WF, et al. Prostacyclin-mediated activation of peroxisome proliferator-activated receptor delta in colorectal cancer. Proc Natl Acad Sci U S A 2000;97:13275-13280.

34. Pawlotsky JM, Chevaliez S, McHutchison JG. The hepatitis C virus life cycle as a target for new antiviral therapies. Gastroenterology 2007;132:1979-1998.

35. Wohnsland A, Hofmann WP, Sarrazin C. Viral determinants of resistance to treatment in patients with hepatitis C. Clin Microbiol Rev 2007;20:23-38. 
1 Author names in bold designate shared co-first authorship. 


\section{Figure Legends.}

2 Figure 1. PG synthase mRNA expression under 3D culture conditions. (A) Results of

3 microarray analysis. Black and white bars represent mRNA expression levels in HuS-

4 E/2 cells cultured with Mebiol gel and hollow fibers, respectively, relative to levels

5 observed in cells cultured under 2D conditions. Gray bars represent mRNA expression

6 levels in HuS-E/2 cells cultured with Mebiol gel by quantifying with quantitative RT-

7 PCRs. qRT-PCR data shows that averages from quadruplicate samples in two

8 independent experiments \pm SD are shown. * differs from Control, $P<.01$; ${ }^{* *}$ differs from

9 Control, $P<.001$. (B) Protein levels of TXAS and various PG synthases in 2D-cultured

10 and 3D-cultured HuS-E/2 cells. PG synthases except for TXAS were detected in whole

11 cell lysate. Asterisks show the result in membrane fraction.

13 Figure 2. Effects of FR122047 on HCVcc-producing Huh-7 cells. (A) Effects of

14 FR122047 on HCV RNA levels in cultured HCVcc-producing cells. HCV RNA was

15 collected from the medium (black bars) and cells (white bars), which were treated with

16 FR122047 at the indicated concentrations. Mean cell viability \pm SD for each sample

17 condition is also plotted (gray bars). Averages from quadruplicate samples in two

18 independent experiments \pm SD are shown. (B) Effects of FR122047 on the infectivity of

19 HCVcc produced using this cell culture system. (C) FR122047 reduces infectious

$20 \mathrm{HCV} c \mathrm{c}$ in the culture medium. Huh-7.5 cells infected with HCVcc from the culture

21 medium of cells treated with (right panel) and without (left panel) FR122047 at the

22 indicated concentrations were stained with anti-HCV antibodies (magenta) and the [Insert Running title of $<72$ characters] 
1 nuclear stain 4',6-diamidino-2-phenylindole (DAPI; cyan). Lower panels show infected

2 cells at lower titer of inoculums. ${ }^{*}$ differs from Control, $P<.01 ;{ }^{* *}$ differs from Control, $P$ $3<.001$.

4

5 Figure 3. Effect of TXAS on infectious HCV production. (A) siRNA-mediated knockdown

6 of TXAS mRNA expression. (B) Effects of TXAS-specific siRNA on HCV RNA levels in

7 the HCVcc-producing cell culture system. (C) Effects of control and TXAS-specific

8 siRNA on the infectivity of HCVcc in medium obtained from HCVcc-producing cell

9 cultures were assessed. (D) Effects of Ozagrel on HCV RNA levels were assessed in

10 HCVcc-producing cell cultures. (E) Effects of Ozagrel on the infectivity of HCVcc

11 produced from the cell culture system were assessed. * differs from Control, $P<.01$; ${ }^{* *}$

12 differs from Control, $P<.001$.

14 Figure 4. Role of TP in infectious HCVcc-producing cell cultures. (A) Effects of U-46619 15 and $\mathrm{TXB}_{2}$ on HCV RNA levels in HCVcc-producing cell cultures in the presence of 16 Ozagrel were assessed. (B) The infectivity of HCVcc in culture medium from HCVcc17 producing cells treated with $\mathrm{U}-46619$ or $\mathrm{TXB}_{2}$ in the presence of Ozagrel was assessed.

18 (C) Effect of daltroban on HCV RNA levels in HCVcc-producing cell cultures. (D) The 19 infectivity of $\mathrm{HCV}$ cc in culture medium from HCVcc-producing cells treated with 20 daltroban. * differs from Control, $P<.01 ;{ }^{* *}$ differs from Control, $P<.001$. 
1 Figure 5. Core and NS5A near LDs and the quantity and infectivity of intracellular

2 HCVcc. (A) HCV Core (magenta) and NS5A (cyan) around LDs (yellow) in HCVcc3 producing cells treated with the indicated reagents were observed using

4 immunofluorescence analysis. Nuclei were stained with DAPI (gray). Scale bars, $5 \mu \mathrm{m}$.

5 (B) Levels of intracellular HCV RNA obtained from the cells treated with Ozagrel. (C)

6 The infectivity of intracellular HCV from cells treated with Ozagrel. Averages of triplicate

7 samples from two independent experiments \pm SD are shown. ${ }^{* *}$ differs from Control, $P$ $8<.001$

10 Figure 6. Buoyant density of HCVcc produced from cells treated with Ozagrel. Lower

11 and upper panels show the results of HCVcc from the cells with and without Ozagrel 12 treatment, respectively. HCV RNA (solid line), fraction density (dotted line) and HCV 13 infectivity (white bars) in each fraction collected after ultracentrifugation are shown. 14 Representative results from two independent experiments are shown.

16 Figure 7. Effects of ONO1301, Beraprost, Ozagrel, and Telaprevir on the expansion of 17 bbHCV-infected UPA/SCID mice bearing human hepatocytes. Data are presented as 18 means \pm SD for six (control, diamonds), four (ONO1301, squares; Ozagrel, crosses; 19 Telaprevir, asterisk), and three (Beraprost, triangles) samples. * differs from Control, $P$ $20<.05$. 


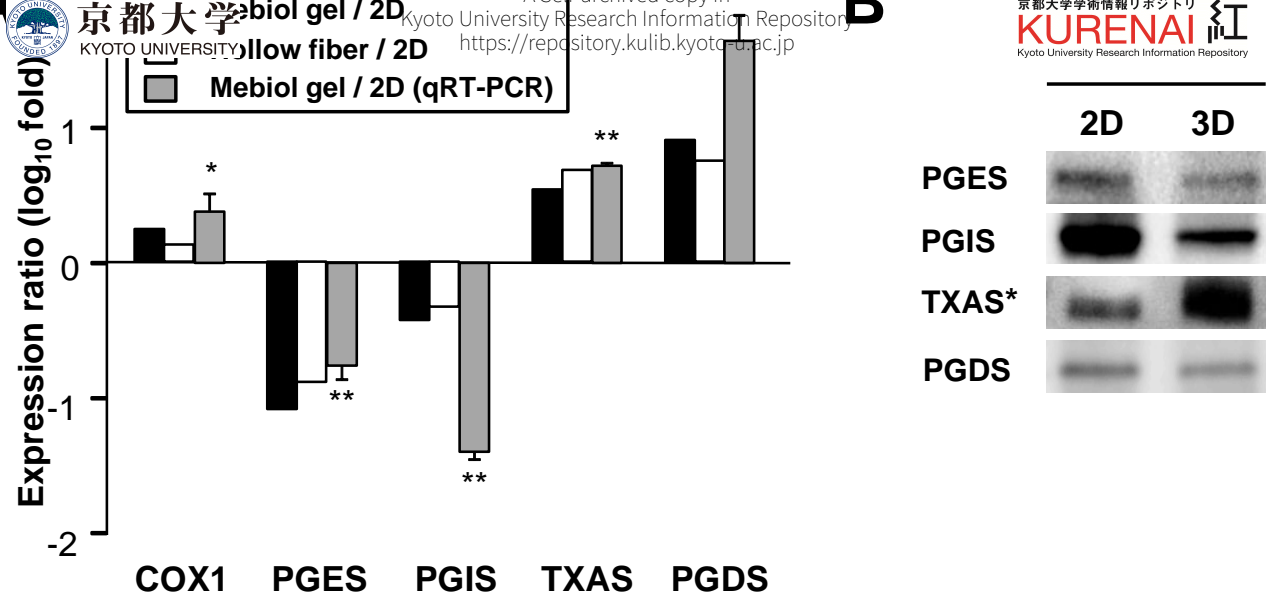




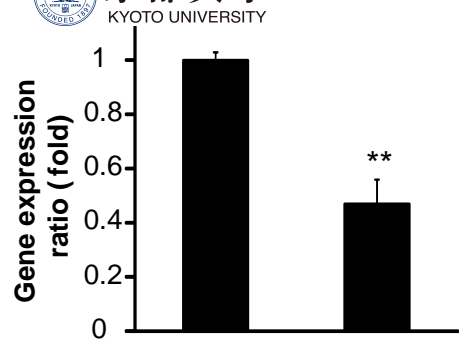

D

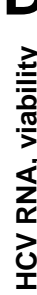

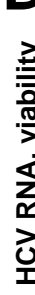

B

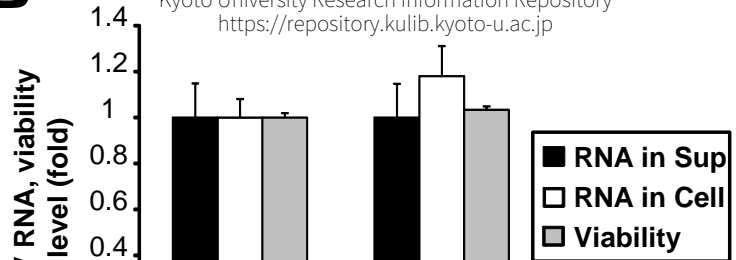

\begin{abstract}
Control siRNA TXAS siRNA $1 \mu \mathrm{M}$

$1 \mu \mathrm{M}$
\end{abstract}

Ozagrel ( $\mu \mathrm{M})$

1.4
1.2
1
0.8
0.6
0.4
0.2
0

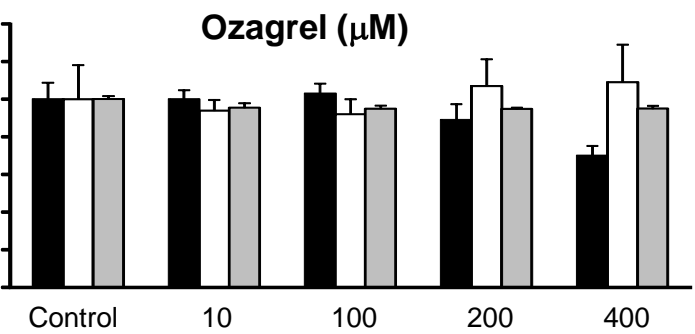

E

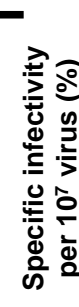

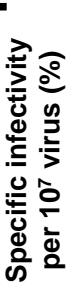

120
100
80
60
40
20
0

$$
1 \mu \mathrm{M}
$$

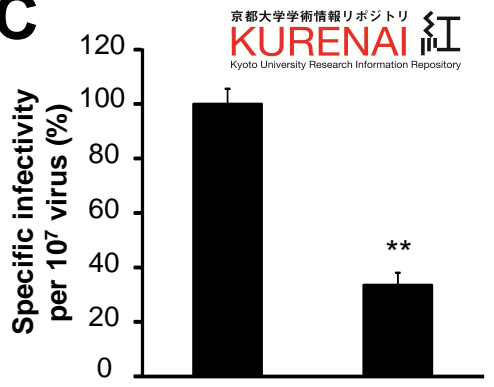

Control siRNA TXAS siRNA $1 \mu \mathrm{M}$
$1 \mu \mathrm{M}$

Ozagrel $(\mu \mathrm{M})$

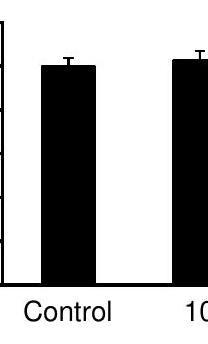

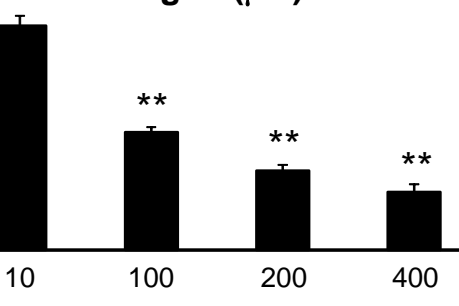




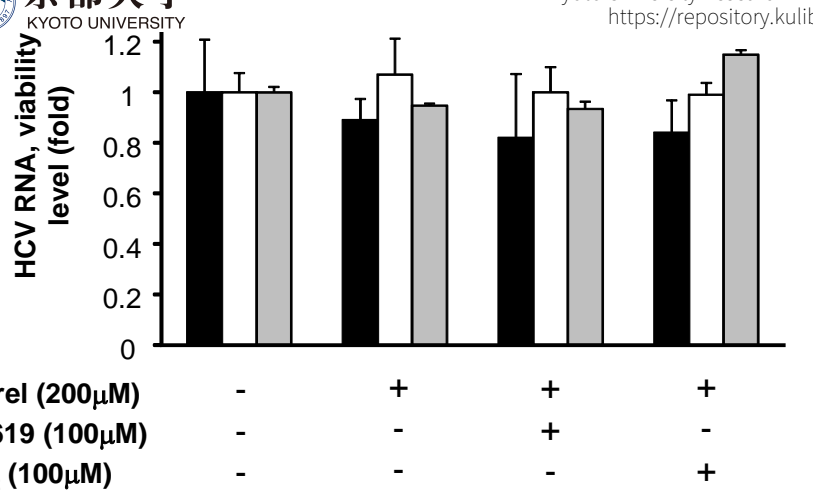

Ozagrel $(200 \mu \mathrm{M})$ $\mathrm{U}-46619(100 \mu \mathrm{M})$ $\mathrm{TXB}_{2}(100 \mu \mathrm{M})$
Daltroban $(\mu \mathrm{M})$

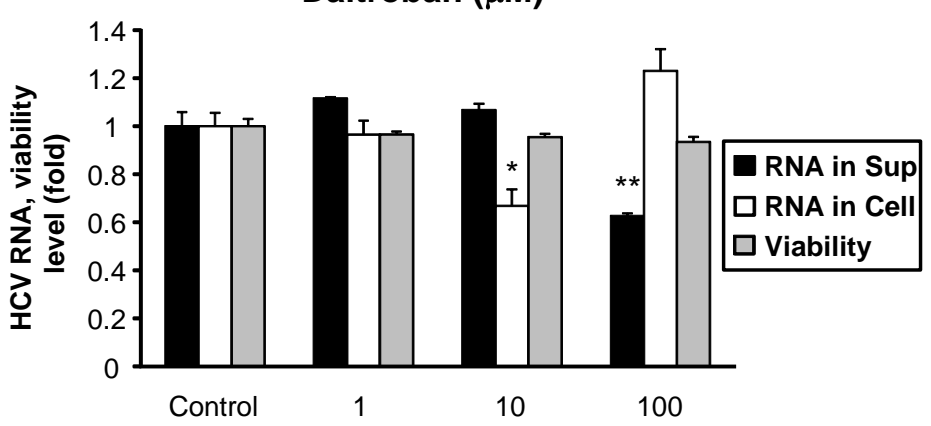

D

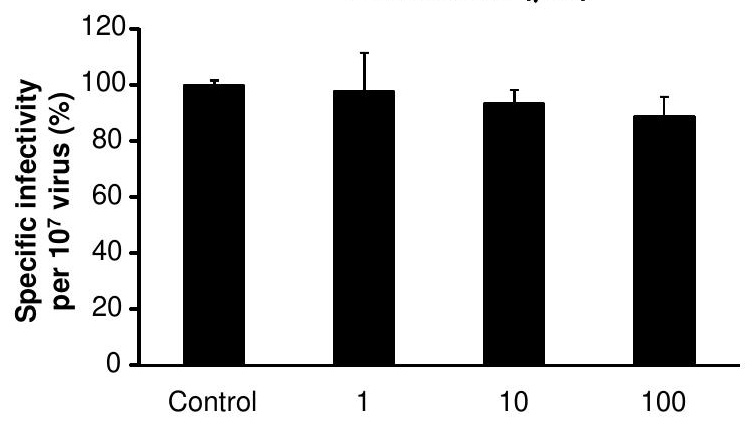


A 京都大学)s

KYOTO UNIVERSITY

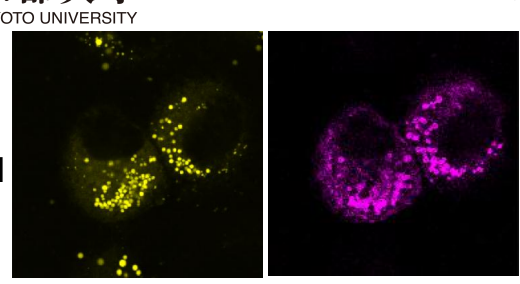

Control
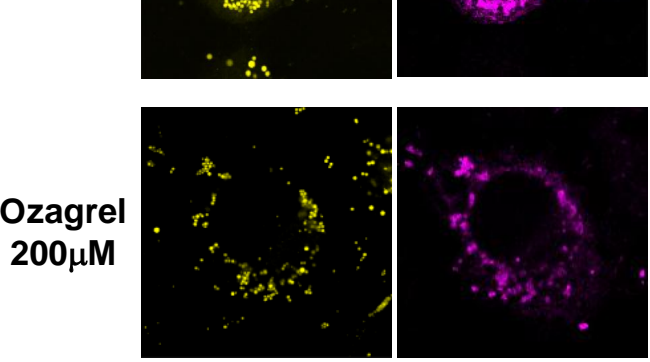

NS5A

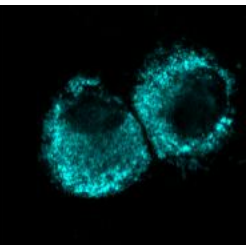

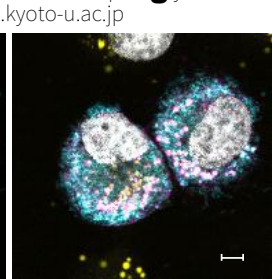
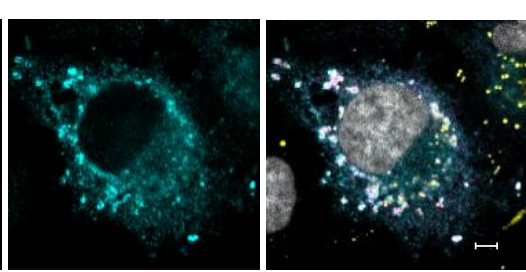

B
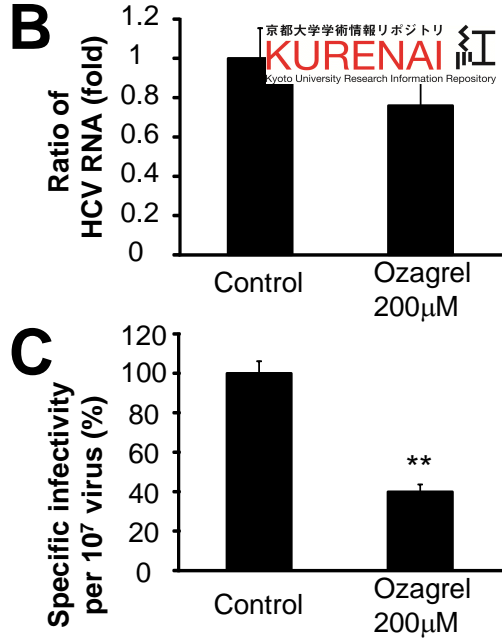


\section{A Self-archived copy in}

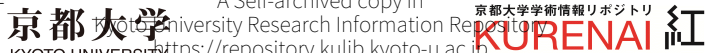

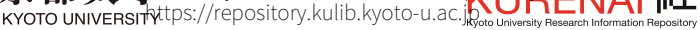

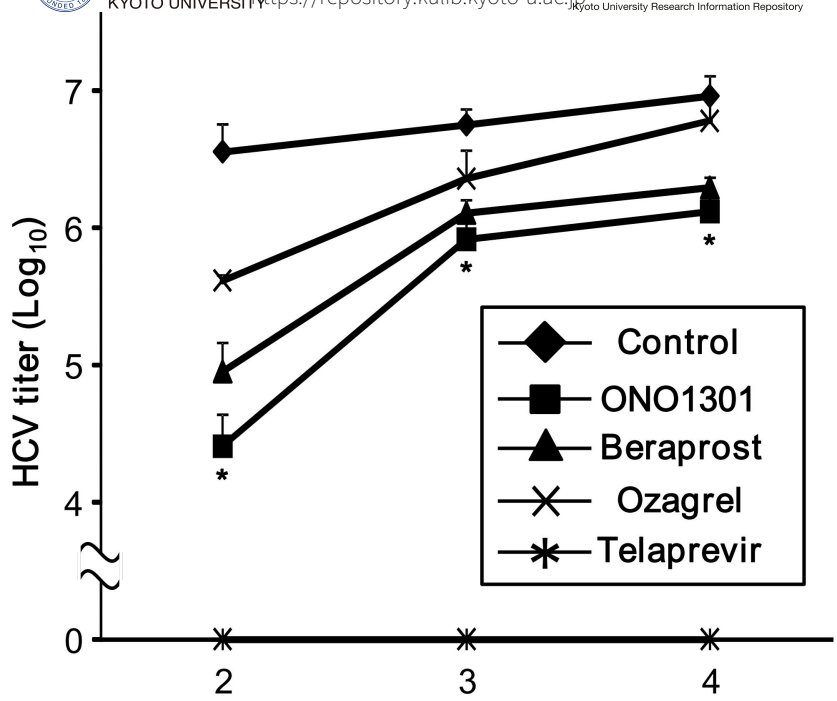

Weeks post-infection 
Supplemental Materials and Methods

2 Preparation of subcellular fraction and protein detection with western blotting

3 Subcellular fractions of HuS-E/2 cells and patient's tissues were prepared by use of

4 ProteoExtract Subcellular proteome Extraction Kit (Millipore, Massachusetts, USA)

5 according to manufacturer's protocol. Five $\mu \mathrm{g}$ of total protein of each fraction or whole

6 cell lysate of each cells was analyze by western blotting. Western blotting was

7 performed as described previously ${ }^{1}$.

9 Collection of total RNA and cell lysate from HCV-infected patients' tissue

10 Total RNA from patients' tissue was collected with RNeasy mini (Qiagen, Hilden,

11 Germany). In briefly, frozen tissues were homogenized in lysis buffer with Power

12 Masher (Nippi, Tokyo, Japan). Homogenized samples were used for RNA purification

13 according to manufacturer's protocol. Cell lysate from tissues were collected with RIPA

14 buffer (Thermo Scientific, Massachusetts, USA) or ProteoExtract Subcellular proteome

15 Extraction Kit according to manufacturer's protocol.

\section{7 cAMP reporter assay}

18 Huh-7-derived and HuS-E/2 cells were transfected with pCRE-Luc (Agilent

19 Technologies, California, USA) using Fugene6 (Roche) and Effectene (Qiagen, Hilden,

20 Germany), respectively, essentially according to the manufacturers' protocols. Six hours

21 and two days post-transfection of Huh-7-derived and HuS-E/2 cells, respectively, the

22 culture medium was replaced with fresh medium containing one of the reagents. One

23 and three day(s) post-transfection of Huh-7-derived and HuS-E/2 cells, respectively,

24 luciferase activity in the cells was measured using a luciferase activity detection reagent

25 (Promega, Wisconsin, USA) and Lumat LB 9507 luminometer (EG\&G Berthold, Bad

26 Wildbad, Germany).

Prostanoid signals as anti-HCV targets 
Yuichi Abe, Makoto Hijikata Page 2

2 Calcium ion quantification

3 HEK293, Huh-7-derived, and HuS-E/2 cells were treated with the calcium ionosphere

4 A23187 (Sigma-Aldrich) and the $\mathrm{TXA}_{2}$ receptor (TP) agonist U-46619 for 1 day. Calcium

5 ion concentrations were quantified using a calcium assay kit (Cayman Chemical)

6 according to the manufacturer's protocols.

8 Actin polymerization assay

9 An activation of actin polymerization via TP was measured with fluorescein

10 isothiocyanate (FITC)-phalloidin (Sigma-Aldrich). After cultured in lipid-free fresh

11 medium, cells were stimulated with $10 \mu \mathrm{M}$ U46619 containing medium for 30, 60, and

$12180 \mathrm{sec}$. Then, samples were stained with $10 \mu \mathrm{g} / \mathrm{ml}$ FITC-phalloidin, Fluorescent

13 intensity at $520 \mathrm{~nm}$ was measured.

\section{Fatty acid analysis}

16 Fatty acid analysis of HCV-infected Huh7.5 cells treated with or without Ozagrel was

17 performed by Toray Research Center, INC. in Japan using gas chromatogray. Total

18 fatty acids samples were extracted from the cells according to Bligh-Dyer method ${ }^{2}$.

20 Secondary infection experiments in chimeric mice transplanted human

\section{1 hepatocyte}

22 The chimeric mice were inoculated intravenously with patient serum including $1.0 \times 10^{5}$

23 genome titer of bbHCV (genotype 1b) as the first infection. Ozagrel was orally

24 administrated twice each day (300 $\mu \mathrm{g} /$ day) one week after the inoculation. The serum

25 samples from those mice were collected at 5 weeks after starting the drug treatments,

26 and used as inocula in the secondary infection experiment. Naïve chimeric mice were Prostanoid signals as anti-HCV targets 
1 inoculated with the collected chimeric mice serum including $1.0 \times 10^{5}$ genome titer of

2 HCV. Administration of Ozagrel was started simultaneously. HCV RNA levels in the

3 blood of the chimeric mice at 1,2 and 3 weeks post infection in secondary infection

4 experiments were evaluated by quantitative RT-PCR.

6 Determination of nucleotide sequence of HCV genome after the treatment of

7 Ozagrel

8 Chimeric mice were secondary inoculated with sera from HCV infected chimeric mice

9 with or without the treatment of Ozagrel. Sera of these chimeric mice treated with or

10 without Ozagrel were collected five weeks after the inoculation and the start of the

11 treatment. HCV genome sequences of these samples were determined by the direct

12 sequencing method according to the protocol described previously ${ }^{3}$. Obtained HCV

13 genomic sequences from sera of mice with two different types of treatment were

14 compared to each other. Mice with two different types of treatments were as follows; A.

15 Mice inoculated secondarily with sera from $1^{\text {st }}$ chimeric mouse without treatment were

16 not treated with the drug (Banklt1626925 Seq3 in GenBank). B. Mice inoculated

17 secondarily with sera from $1^{\text {st }}$ chimeric mouse with treatment were treated with the drug

18 (Banklt1626925 Seq1 in GenBank). These sequencing data were registered with

19 GenBank (http://www.ncbi.nlm.nih.gov/genbank/). 
Yuichi Abe, Makoto Hijikata Page 4

Figure Legends

2 Supplemental Figure 1. Protein and mRNA levels of PG synthases in HCV-infected

3 patient's tissue. (A), (B) mRNA expression and protein levels of PG synthases in HCV-

4 infected patient's tissue. Representative results from two independent experiments are

5 shown.

7 Supplemental Figure 2. Effects of COX2 inhibitor 1 on infectious HCV production. (A)

8 Effects of COX2 inhibitor 1 on HCV RNA levels in the HCVcc-producing cell culture

9 system. Levels of HCV RNA in medium (black bars) and cells (white bars) treated with

10 or without COX2 inhibitor 1 were assessed with quantitative RT-PCRs and are plotted

11 as amounts relative to results observed with control cells (control). Mean cell viability \pm

12 SD for each sample condition is also plotted (gray bars). (B) Effects of COX2 inhibitor 1

13 on the infectivity of HCVcc produced using the cell culture system. (C) Expression of

14 COX2 mRNA in MH14 (positive control), Huh-7, and JFH1-transfected Huh-7 cells. *

15 differs from Control, $P<.01$; ${ }^{* *}$ differs from Control, $P<.001$.

17 Supplemental Figure 3. Expression of $P G$ synthase and PG receptor mRNA in

18 immortalized and primary hepatocyte cell lines. (A), (B) mRNA expression levels of

19 various PG synthases and PG receptors in HuS-E/2 cells, Huh-7 cells, Huh-7.5 cells,

20 and primary human hepatocytes were analyzed in RT-PCRs. Representative results

21 from two independent experiments are shown.

23 Supplemental Figure 4. Effects of short hairpin RNA (shRNA)-mediated knockdown of

24 TXAS mRNA levels on infectious HCV production. (A) Knockdown of TXAS mRNA 25 levels using shRNA. (B) Effects of TXAS-specific shRNA on HCV RNA levels in the 26 HCVcc-producing cell culture system. Levels of HCV RNA in medium (black bars) and Prostanoid signals as anti-HCV targets 
1 cells (white bars) treated with control or TXAS-specific shRNA were assessed with 2 quantitative RT-PCRs and are plotted as amounts relative to results observed with 3 control shRNA-treated cells (control). Mean cell viability \pm SD for each sample condition

4 is also plotted (gray bars). (C) Effects of TXAS-specific shRNA on the infectivity of 5 HCVcc produced using the cell culture system. ${ }^{* *}$ differs from Control, $P<.001$.

7 Supplemental Figure 5. Effects of Ozagrel and ONO1301 on the infectivity of HCVcC 8 produced from J6/JFH1-transfected Huh-7.5 cells. (A) Effects of Ozagrel (upper panel) 9 and ONO1301 (lower panel) on HCV RNA levels in HCVcc-producing cell cultures.

10 Levels of HCV RNA in the medium (black bars) and cells (white bars) treated with

11 Ozagrel or ONO1301 cells were assessed in quantitative RT-PCRs and are plotted as

12 the amount relative to results from untreated cells (control). Mean cell viability \pm SD for

13 each sample condition is also plotted (gray bars). (B) Effects of Ozagrel (upper panel)

14 and ONO1301 (lower panel) on the infectivity of HCVcc produced in the cell culture 15 system. * differs from Control, $P<.01 ;{ }^{* *}$ differs from Control, $P<.001$.

17 Supplemental Figure 6. Effects of $\mathrm{PGH}_{2}$ on infectious HCV production. (A) Effects of $18 \mathrm{PGH}_{2}$ on HCV RNA levels in the HCVcc-producing cell culture system. Levels of HCV 19 RNA in medium (black bars) and cells (white bars) treated with or without $\mathrm{PGH}_{2}$ were 20 assessed with quantitative RT-PCRs and are plotted as amounts relative to results 21 observed with control cells (control). Mean cell viability \pm SD for each sample condition 22 is also plotted (gray bars). (B) Effects of $\mathrm{PGH}_{2}$ on the infectivity of $\mathrm{HCV}$ cc produced 23 using the cell culture system. ${ }^{*}$ differs from Control, $P<.01 ;{ }^{* *}$ differs from Control, $P$ $24<.001$. 
Yuichi Abe, Makoto Hijikata Page 6

1 Supplemental Figure 7. Effects of $\mathrm{U}-46619$ and $\mathrm{TXB}_{2}$ on infectious $\mathrm{HCV}$ production.

2 (A) Effects of U-46619 (upper panel) and $\mathrm{TXB}_{2}$ (lower panel) on HCV RNA levels in

3 HCVcc-producing cell cultures. Levels of HCV RNA in the medium (black bars) and cells

4 (white bars) treated with $\mathrm{U}-46619$ or $\mathrm{TXB}_{2}$ were assessed in quantitative RT-PCRs and

5 are plotted as the amount relative to results observed with untreated cells (control).

6 Mean cell viability \pm SD for each sample condition is also plotted (gray bars). (B) Effects

7 of U-46619 (upper panel) and $\mathrm{TXB}_{2}$ (lower panel) on the infectivity of HCVcc produced

8 in the cell culture system were assessed.

10 Supplemental Figure 8. Effects of U-46619 on HuS-E/2, Huh-7, Huh-7.5, and HEK293

11 cell lines via TP. (A) Concentrations of intracellular calcium ions were measured in HuS-

12 E/2 (black bars), Huh-7 (white bars), Huh-7.5 (gray bars), and HEK293 (dark gray bars)

13 cells treated with or without a calcium ionophore or U-46619. Calcium ion

14 concentrations relative to those in mock treated cells (control) were determined from

15 triplicate wells in two independent experiments and are shown as means \pm SD. (B) Actin

16 polymerization after U-46619 treatment was measured with FITC-labeled phalloidin. *

17 differs from Control, $P<.01 ;{ }^{* *}$ differs from Control, $P<.001$

19 Supplemental Figure 9. Effects of $\mathrm{PGI}_{2}$ on infectious $\mathrm{HCV}$ production. (A) siRNA-

20 mediated knockdown of PGIS expression. (B) Effects of PGIS-specific siRNA on HCV

21 RNA levels in HCVcc-producing cell cultures. Levels of HCV RNA in medium (black

22 bars) and cells (white bars) treated with control or PGIS-specific siRNA were assessed

23 in quantitative RT-PCR and are plotted as amounts relative to results obtained with

24 control siRNA-treated cells (control). Mean cell viability \pm SD for each sample condition

25 is also plotted (gray bars). (C) Effects of PGIS-specific siRNA on the infectivity of HCVcc

26 produced in the cell culture system. (D) Effects of Beraprost on HCV RNA levels in Prostanoid signals as anti-HCV targets 
HCVcc-producing cell cultures. Levels of HCV RNA in medium (black bars) and HCVccproducing Huh-7 cells (white bars) treated with Beraprost were assessed in quantitative

3 RT-PCRs and are plotted as amounts relative to results obtained with untreated cells

4 (control). Mean cell viability \pm SD for each sample condition is also plotted (gray bars).

5 (E) Effects of Beraprost on the infectivity of HCVcc in culture medium from HCVcc6 producing cell cultures were assessed. * differs from Control, $P<.01$

Supplemental Figure 10. Effects of ONO1301 on HCV lifecycle. (A) Levels of HCV

9 RNA in medium (black bars) and cells (white bars) treated with or without ONO1301

10 were assessed. Mean cell viability \pm SD for each sample condition is also plotted (gray

11 bars). (B) The infectivity of HCVcc in culture medium from HCVcc-producing cell

12 cultures treated with or without ONO1301 was assessed. (C) Subcellular locations of

$13 \mathrm{HCV}$ Core and NS5A proteins around LDs in the presence of ONO1301. Scale bars, 5

$14 \mu \mathrm{m}$. (D), (E) Levels and infectivity of intracellular HCV obtained from the cells treated

15 with ONO1301. (F) Buoyant density of HCVcc obtained using cells treated with

16 ONO1301. The panel shows HCV RNA (solid line), fraction density (dotted line) and

$17 \mathrm{HCV}$ infectivity (white bars) in each fraction collected by ultracentrifugation. * differs

18 from Control, $P<.01 ;{ }^{* *}$ differs from Control, $P<.001$.

20 Supplemental Figure 11. Effects of dibutyryl cAMP (dbcAMP) on cell cultures

21 producing JFH1 HCVcc. (A) HuS-E/2 (black bars), Huh-7 (white bars), and Huh-7.5

22 (gray bars) cells were transfected with CRE-Luc plasmid. Then, the luciferase activity in

23 each sample was measured. Values were obtained from quadruplicate wells in two

24 independent experiments and are shown as means \pm SD. (B) Effects of dbcAMP on

25 HCV RNA levels in HCVcc-producing cell cultures. Levels of HCV RNA in medium 26 (black bars) and cells treated with dbcAMP (white bars) were assessed in quantitative Prostanoid signals as anti-HCV targets 
1 RT-PCRs and are plotted as amounts relative to results obtained with mock-treated

2 cells (control). Mean cell viability \pm SD for each sample condition is also plotted (gray

3 bars). (C) Effects of dbcAMP on the infectivity of HCVcc produced using the cell culture

4 system. ${ }^{*}$ differs from Control, $P<.01 ;{ }^{* *}$ differs from Control, $P<.001$.

6 Supplemental Figure 12. Comparison of composition of fatty acids in HCV-infected

7 Huh7.5 cells with or without the treatment of Ozagrel.

9 Supplemental Figure 13. Expression of TP mRNA in liver tissues from Human patients

10 and chimeric mice infected with HCV.

12 Supplemental Figure 14. Secondary infection of HCV derived from chimeric mice

13 model. Data are presented as means \pm SD for four samples.

15 Supplemental Figure 15. Base substitutions in HCV genome collected from mice

16 serum during secondary infection. HCV genomic sequences from mice sera with the

17 treatment of Ozagrel during primary and secondary infection was compared to those

18 from mice without any treatment during both infection experiments. The region of

19 obtained HCV genomic sequences is indicated by a thick bar. The nucleotide positions

20 of each base substitution are shown with arrows. Positions of base substitutions, and

21 types of base substitution and amino acid replacement are listed at lower panel. 
[First Authors Last Name] Page 9

1 Tables

2 Supplemental Table 1. Primer sequences and parameters in RT-PCR experiments.

3 RT-PCRs were performed as follows: $25-40$ cycles of $95^{\circ} \mathrm{C}$ for 30 seconds, $55-62^{\circ} \mathrm{C}$ for

430 seconds, and $72^{\circ} \mathrm{C}$ for 1 minute.

5

6 Supplemental Table 2. Primer sequences and parameters in qRT-PCR experiments.

7 qRT-PCRs were performed as follows: 40 cycles of $95^{\circ} \mathrm{C}$ for 5 seconds, $60^{\circ} \mathrm{C}$ for 34

8 seconds.

\section{Supplemental Reference}

11 1. Kushima Y, Wakita T, Hijikata M. A disulfide-bonded dimer of the core protein of hepatitis $\mathrm{C}$ virus is important for virus-like particle production. J Virol 2010;84:9118-9127.

$142 . \quad$ Bligh EG, Dyer WJ. A rapid method of total lipid extraction and purification. Can J Biochem Physiol 1959;37:911-917.

16 3. Kimura T, Imamura M, Hiraga N, et al. Establishment of an infectious genotype 1b hepatitis $C$ virus clone in human hepatocyte chimeric mice. J Gen Virol 2008;89:2108-2113.

[Insert Running title of $<72$ characters] 


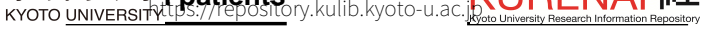

No.

1

2

3

cox1

cox2

PGES

PGIS

TXAS

PGDS

GAPDH

RT-

(GAPDH)
No. 1123

PGES

PGIS

TXAS

PGDS

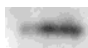

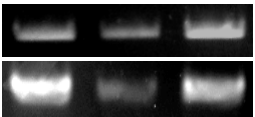
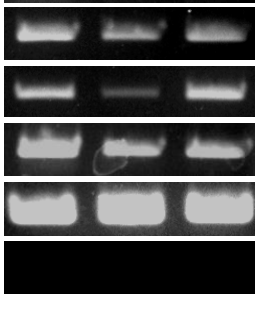


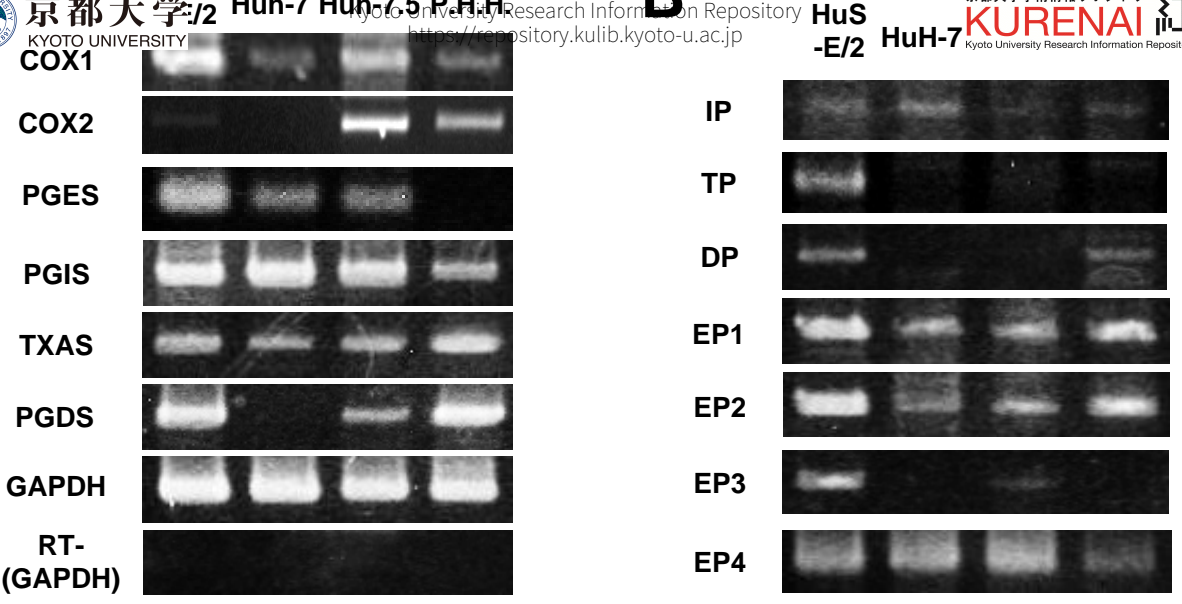

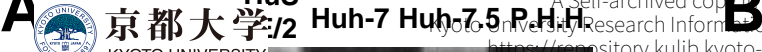
KYOTO UNIVERSTY 


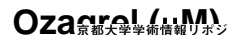

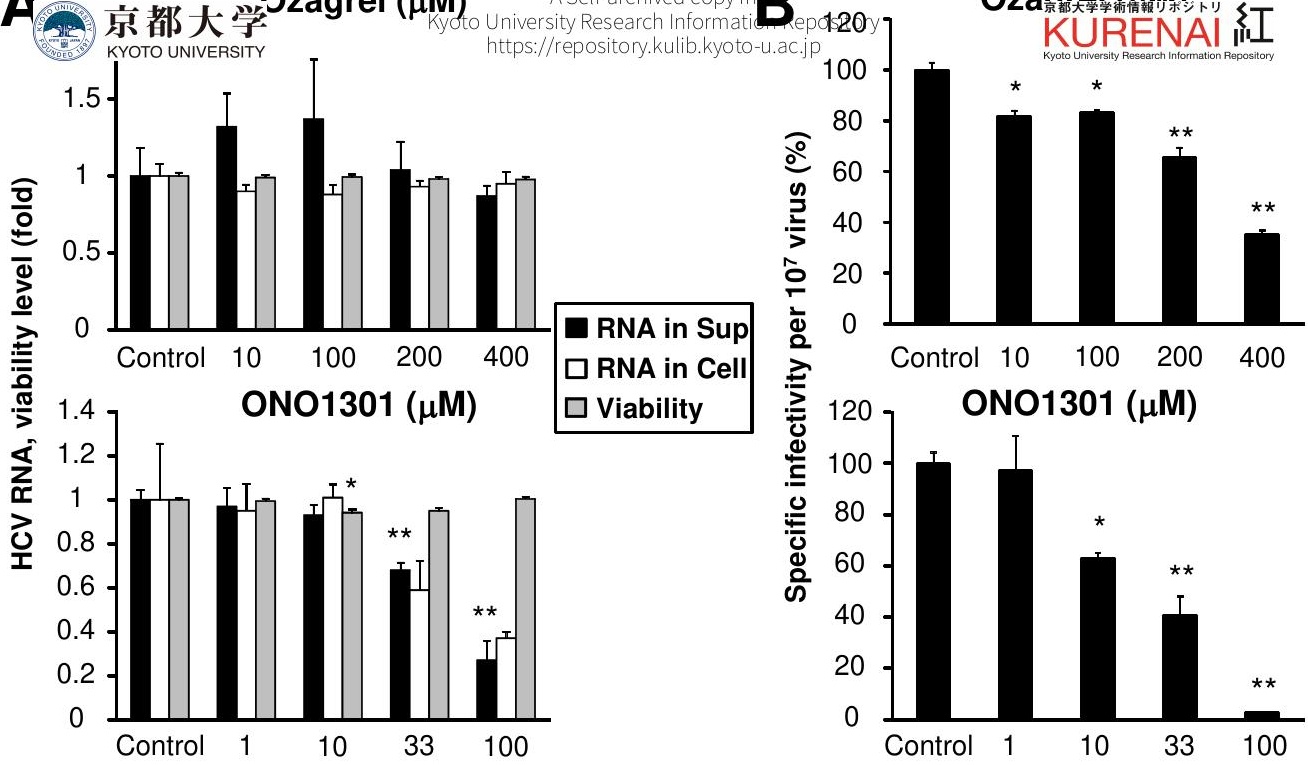


KYOTO UNIVERSITY

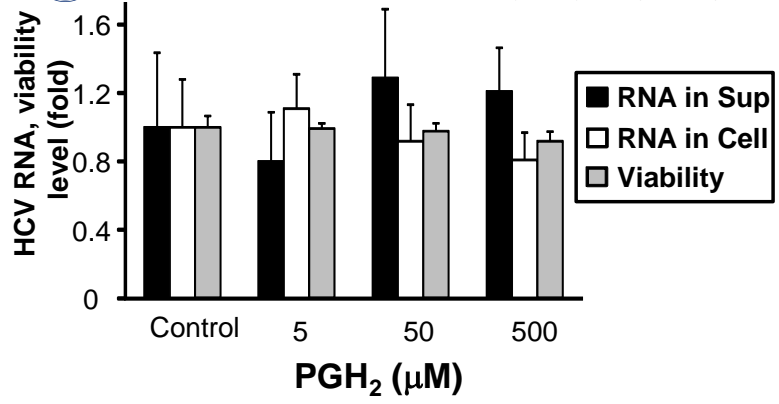

京都大学学術情報リポジトリ

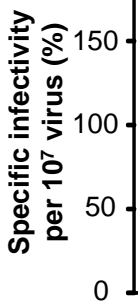
Control

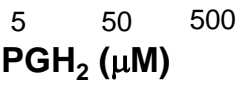


$A_{12}$ 京都大学-46619 ( $\left.\mu \mathrm{M}\right)$

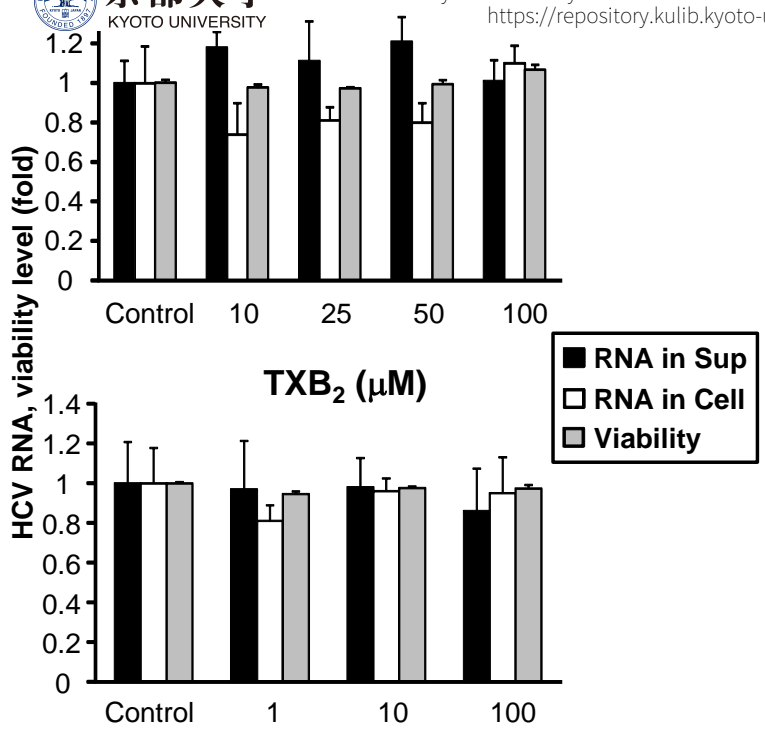

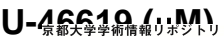
KURENAI II Kyoto University Research Information Repository

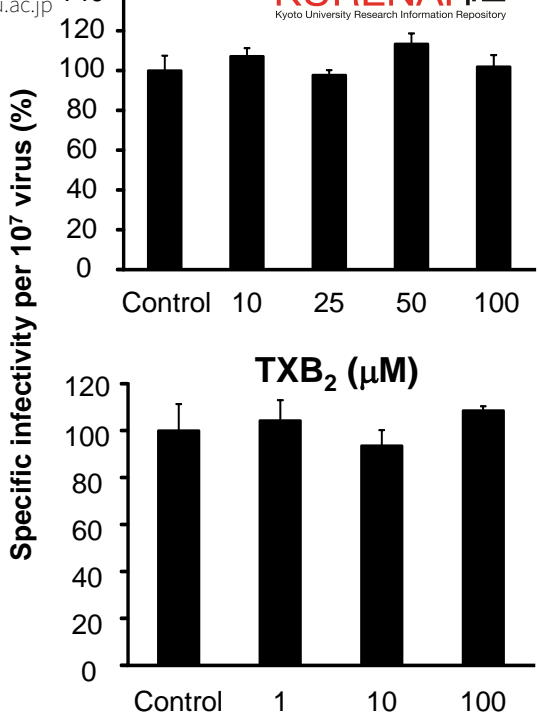




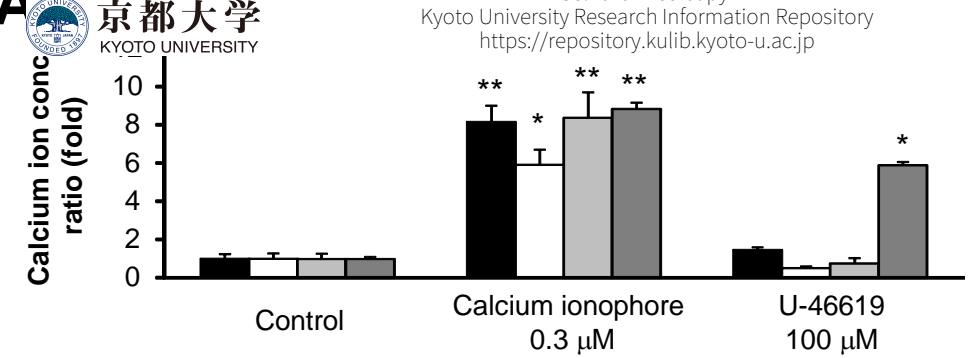

B

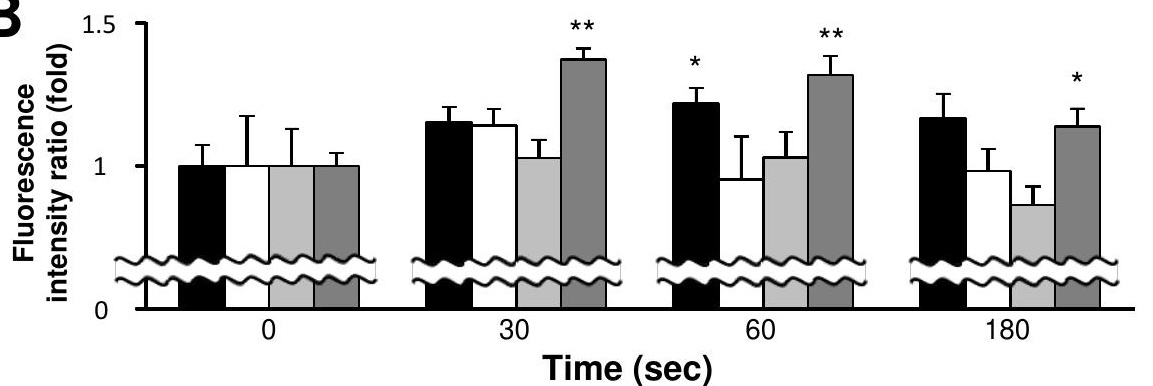



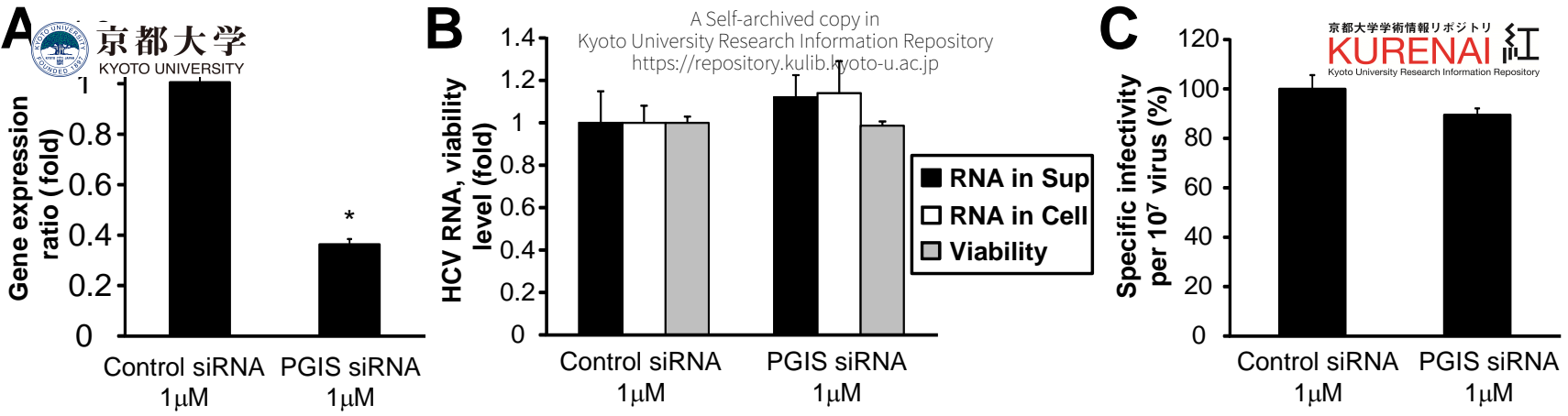

D

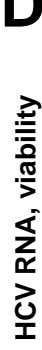

Beraprost $(\mu \mathrm{M})$
1.4 1.2
1.2

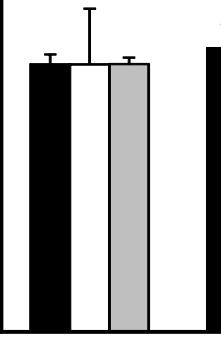

Control

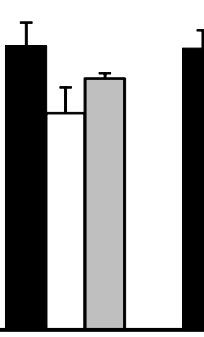

50

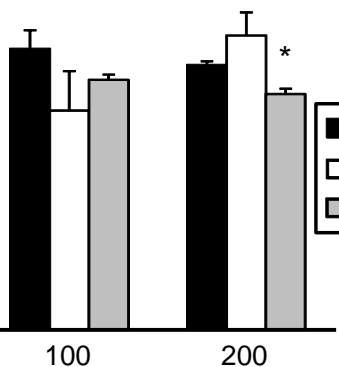

E

RNA in Sup $\square$ RNA in Cell $\square$ Viability
Beraprost $(\mu \mathrm{M})$

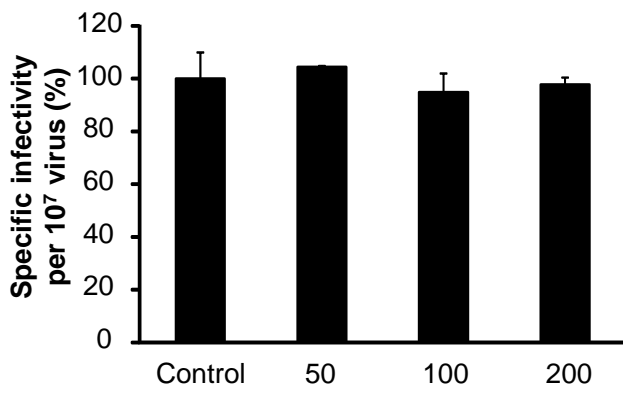




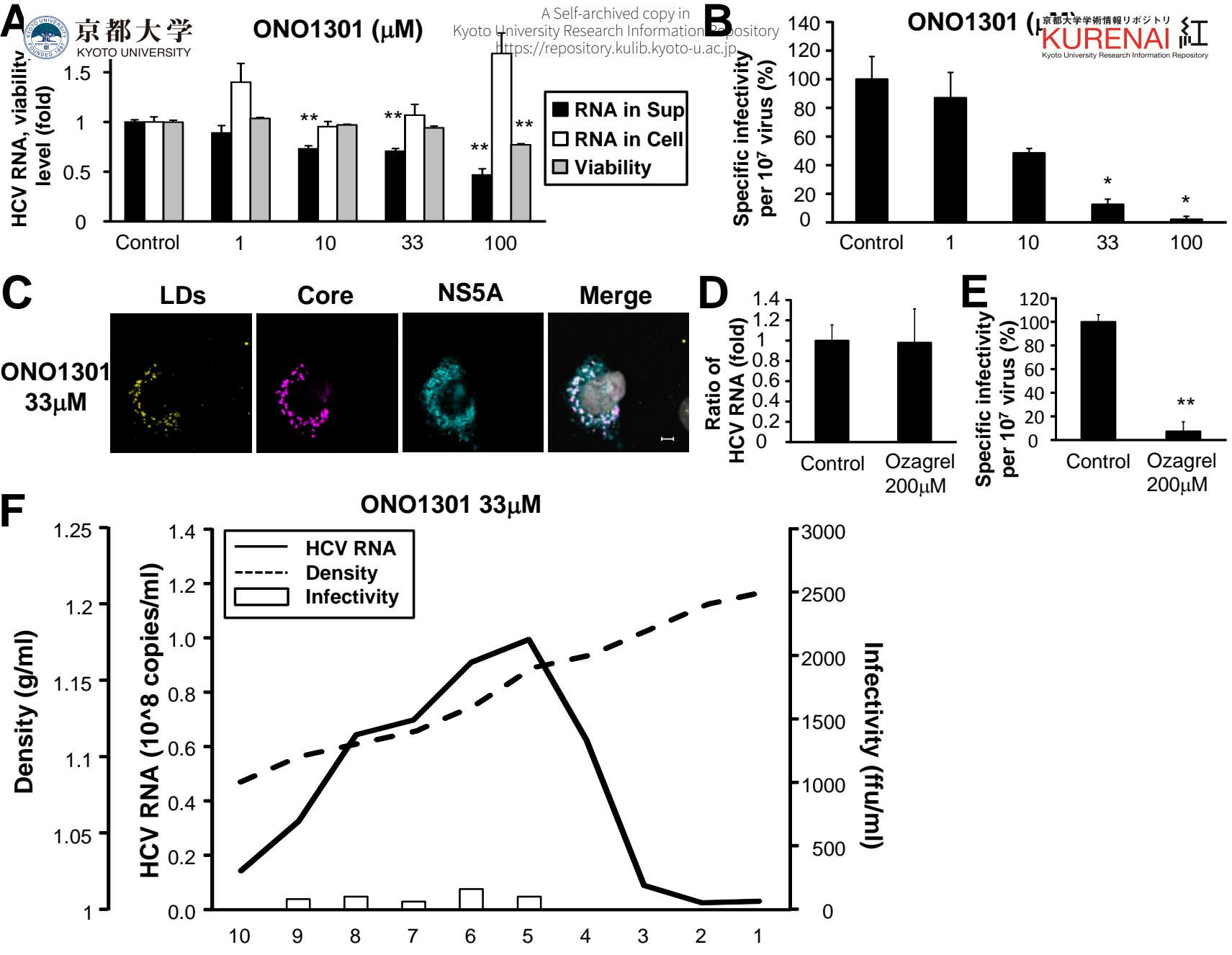



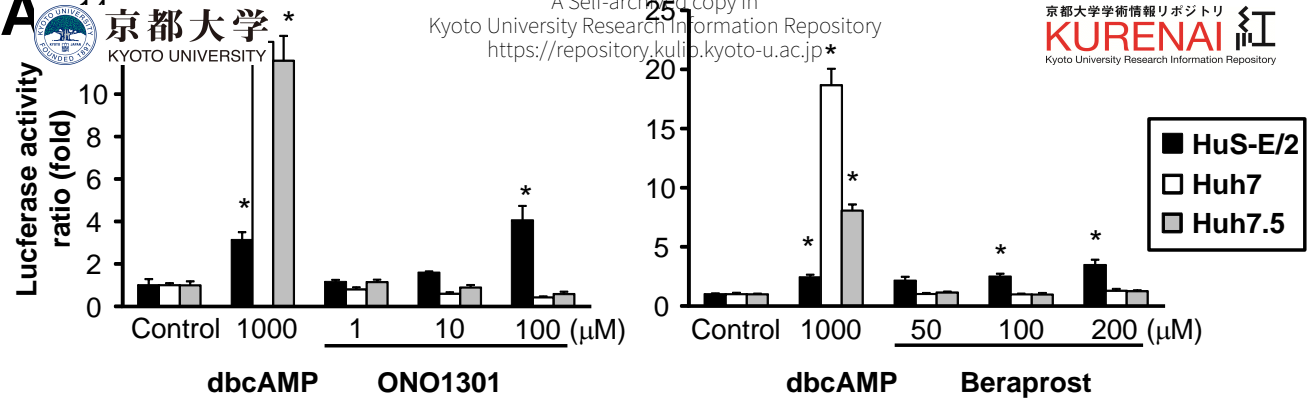

B
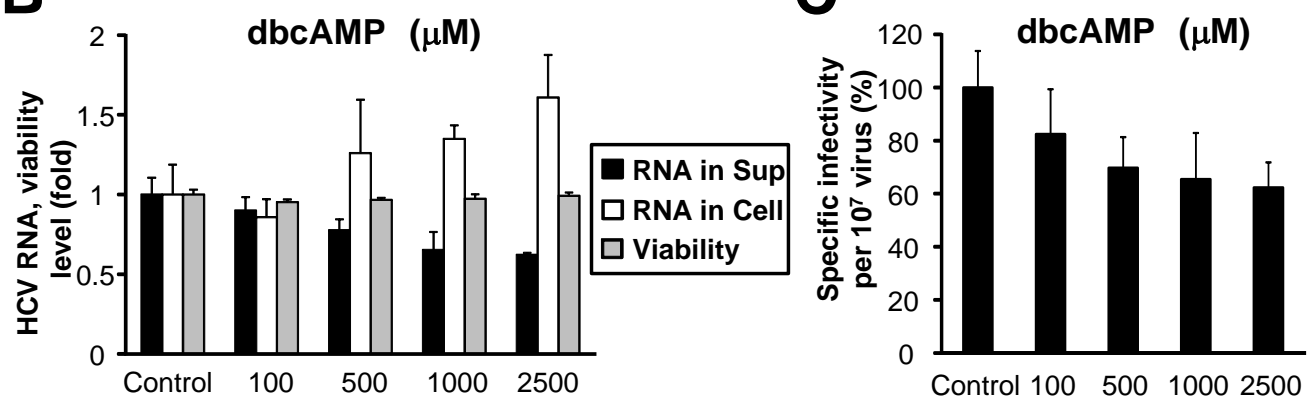


\section{政大学}

(3YOTO UNIVERSITY

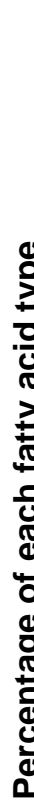

$25-$

20

15

10
5

0

C 14:0 C 14:1 C 16:0 C 16:1 C 17:0 C 18:0 C 18:1 C 18:2 C 20:0 C 20:1 C 20:2 C 20:3 C 20:4 C 20:5 C 24:0 C 24:1 C 22:6 $\omega-6$ $\omega-6$ $\omega-6$ $\omega-6$ $\omega-3$ $\omega-3$ 


\section{A Self-archived copy in}

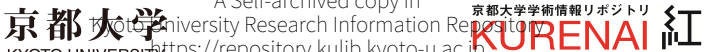
KYOTO UNIVERSITtxtps://repository. kulib. kyoto-u.ac. jhyoto University Research Intormation Repository

\section{HCV positive Liver tissue}

TP

\section{GAPDH}

\section{Human Mice}
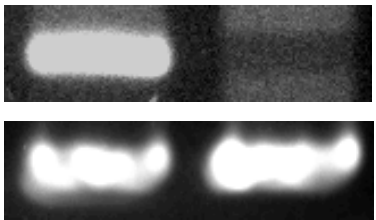

RT-

(GAPDH)

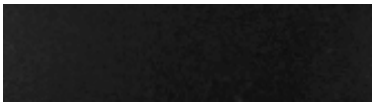




\section{A Self-archived copy in}

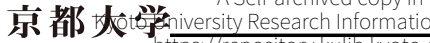

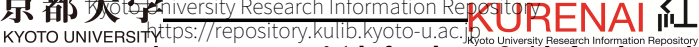

$\mathbf{1}^{\text {st }}$ infection $\mathbf{2}^{\text {na }}$ infection

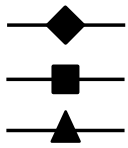
Control
Ozagrel
Ozagrel

Control

Control

Ozagrel

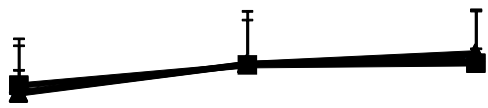

6

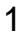

2

3

Weeks post-infection 


\begin{tabular}{|c|c|c|c|c|}
\hline \multirow[t]{2}{*}{$\begin{array}{l}\text { 京都大学 } \\
\text { KYOTO UNIVERITY }\end{array}$} & NS2 & $\begin{array}{l}\text { University NSS } \\
\text { https://repository.kulib.kyo }\end{array}$ & 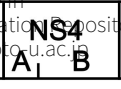 & \multirow{2}{*}{ 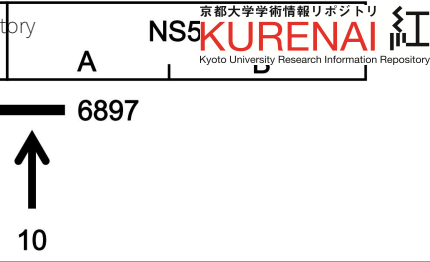 } \\
\hline & 12 & 3,45 & 9 & \\
\hline $\begin{array}{c}\text { Number of } \\
\text { substitution point }\end{array}$ & $\begin{array}{l}\text { Position of } \\
\text { nucleotide }\end{array}$ & $\begin{array}{l}\text { Single base } \\
\text { substitution }\end{array}$ & & Amino acid replacement \\
\hline 1 & 3192 & $A \rightarrow G$ & & Asparagine $\rightarrow$ Aspartic acid \\
\hline 2 & 3264 & $A \rightarrow G$ & & Isoleucine $\rightarrow$ Valine \\
\hline $\begin{array}{l}3 \\
4\end{array}$ & $\begin{array}{l}3596 \\
3597\end{array}$ & $\begin{array}{l}\mathrm{T} \rightarrow \mathrm{A} \\
\mathrm{C} \rightarrow \mathrm{T}\end{array}$ & & Phenylalanine $\rightarrow$ Tyrosine \\
\hline 5 & 3859 & $\mathrm{C} \rightarrow \mathrm{T}$ & & Serine $\rightarrow$ Leucine \\
\hline 6 & 4283 & $\mathrm{G} \rightarrow \mathrm{A}$ & & Methionine $\rightarrow$ Isoleucine \\
\hline $\begin{array}{l}7 \\
8\end{array}$ & $\begin{array}{l}4437 \\
4439\end{array}$ & $\begin{array}{l}\mathrm{G} \rightarrow \mathrm{A} \\
\mathrm{T} \rightarrow \mathrm{C}\end{array}$ & & Glycine $\rightarrow$ Serine \\
\hline 9 & 5886 & $\mathrm{G} \rightarrow \mathrm{A}$ & & Valine $\rightarrow$ Methionine \\
\hline 10 & 6747 & $\mathrm{G} \rightarrow \mathrm{A}$ & & Alanine $\rightarrow$ Threonine \\
\hline
\end{tabular}


COX1 F: GCAGCTGAGTGGCTATTTCC R: ATCTCCCGAGACTCCCTGAT

$\operatorname{cox} 2$

F: GCAGTTGTTCCAGACAAGCA

R: GGTCAATGGAAGCCTGTGAT

PGES

F: GAAGAAGGCCTTTGCCAAC

R: GGAAGACCAGGAAGTGCATC

PGDS

F: AAGGCGGCGTTGTCCATGTGCAAGTC

R: ATTGTTCCGTCATGCACTTATC

PGIS

F: TCCTGGACCCACACTCCTAC

R: GCGAAAGGTGTGGAAGACAT

TXAS

F: TCTGCATCCCCAGACCTATC

R: ATAGCCAGCGATGAGGAAGA

GAPDH

F: ATGGGGAAGGTGAAGGTCGG

R: TGGAGGGATCTCGCTCCTGG

F: GGTATCATGGTGGTGTCGTG

R: GGCCTCTGGTTGTGCTTAGA

F: AGGAGAGGGGAAAGGGTGT

EP2

R: TCTTAATGAAATCCGACAACAGAG

F: GACAGTCACCTTTTCCTGCAAC

EP3

R: AGGCGAACAGCTATTAAGAAGAAG

EP4

F: CAGGACATCTGAGGGCTGAC

R: GTAGAAGGTCGTCTCCTTCTGCTC

F: GCAACCTCTATGCGATGCAC

R: GGGTCCACAATTGAAATCAC

IP

TP
F: AAGACTGGAGAGCCCAGACC

R: CCACGAACATCAGGGTGCTG

F: CAGATGAGGTCTCTGAAGGTGTG R: CAGAGGAAGGTGAGGAAGGAG

324

60

32

383

60

35

200

62

35

400

\section{5}

40

395

60

40

374

60

40

250

60

40

324

60

40

267

60

40

276

60

40

269

60

40

292

60

32

161

60

40

304

60 


\section{$\operatorname{cox} 1$}

F: TCCGGTTCTTGCTGTTCCTG

R: TCACACTGGTAGCGGTCAAG

151

PGES

F: CATCCTCTCCCTGGAAATCTCG

R: CCGCTTCCTACTGTGACCC

129

PGDS

F: CCTGTCCACCTTGCACAGTC

R: TCATGCTTCGGTTCAGGACG

123

PGIS

F: GCAGTGTCAAAAGTCGCCTG

R: ACTCTCCAGCCATTTGCTCC

83

TXAS

F: TTTGCTTGGTTGCCTGTTCC

R: CCAGAGTGGTGGTCTTCCAG

99

GAPDH

F: GACAGTCAGCCGCATCTTCT

R: GCGCCCAATACGACCAAATC 